\title{
Pharmacogenetic testing and therapeutic drug monitoring are complementary tools for optimal individualization of drug therapy
}

\author{
Guillermo Gervasini • Julio Benítez • \\ Juan Antonio Carrillo
}

Received: 18 February 2010 / Accepted: 2 June 2010 / Published online: 27 June 2010

(C) Springer-Verlag 2010

\begin{abstract}
Genetic factors contribute to the phenotype of drug response, but the translation of pharmacogenetic outcomes into drug discovery, drug development or clinical practice has proved to be surprisingly disappointing. Despite significant progress in pharmacogenetic research, only a few drugs, such as cetuximab, dasatinib, maraviroc and trastuzumab, require a pharmacogenetic test before being prescribed. There are several gaps that limit the application of pharmacogenetics based upon the complex nature of the drug response itself. First, pharmacogenetic tests could be more clinically applicable if they included a comprehensive survey of variation in the human genome and took into account the multigenic nature of many phenotypes of drug disposition and response. Unfortunately, much of the existing research in this area has been hampered by limitations in study designs and the nonoptimal selection of gene variants. Secondly, although responses to drugs can be influenced by the environment, only fragmentary information is currently available on how the interplay between genetics and environment affects drug response. Third, the use of a pharmacogenetic test as a standard of care for drug therapy has to overcome significant scientific, economic, commercial, political and educational barriers, among others, in order for clinically
\end{abstract}

G. Gervasini $\cdot$ J. Benítez $\cdot$ J. A. Carrillo

Department of Medical and Surgical Therapeutics, Division of Clinical Pharmacology, Medical School, University of Extremadura,

06071 Badajoz, Spain

J. Benítez $(\square)$

Departamento de Terapéutica Médico-Quirúrgica,

Unidad de Farmacología Clínica, Facultad de Medicina,

Universidad de Extremadura,

06071 Badajoz, España

e-mail: jbenitez@unex.es useful information to be effectively communicated to practitioners and patients. Meanwhile, the lack of efficacy is in this process is quite as costly as drug toxicity, especially for very expensive drugs, and there is a widespread need for clinically and commercially robust pharmacogenetic testing to be applied. In this complex scenario, therapeutic drug monitoring of parent drugs and/or metabolites, alone or combined with available pharmacogenetic tests, may be an alternative or complementary approach when attempts are made to individualize dosing regimen, maximize drug efficacy and enhance drug safety with certain drugs and populations (e.g. antidepressants in older people).

Keywords Pharmacogenetics · Biomarkers · Therapeutic drug monitoring (TDM) $\cdot$ Personalized medicine

\section{Introduction}

Despite the continuous advances in the discovery and design of drugs, the interindividual variability to the standard dose of a given drug remains a serious problem in clinical practice. Drug treatment is, in many cases, ineffective with a high number of non-responders (30-60\%) to drug therapy [1]. Moreover, serious adverse drug reactions (ADRs) cause or contribute to $6-7 \%$ of all hospitalizations, a 2-day increase in the average length of hospitalization and over 100,000 deaths annually in the USA and may, according to some estimates, cost about as much as the drug treatment itself [2].

A significant portion of the variability in drug response can be attributed to genetic factors through modulation of drug pharmacokinetics and/or pharmacodynamics. Therefore, the rationale behind pharmacogenetics is to deal with genes encoding drug transporters, drug-metabolizing 
enzymes and drug targets that can predict the usefulness of a particular drug so as to increase the number of responders and decrease the number of subjects affected by ADRs. Within this framework, our current level of knowledge is most advanced regarding the influence of polymorphically distributed genes encoding drug-metabolizing enzymes, in particular, the cytochrome P450s (CYPs), which have the highest impact on interindividual differences in drug response. However, our knowledge of drug transporters and receptors is rapidly growing.

There are 57 known active CYP genes in the human genome and 58 pseudogenes (http://drnelson.uthsc.edu/ CytochromeP450.html; [3]). The CYP enzyme families 13 are generally polymorphic and responsible for $70-80 \%$ of all phase I-dependent metabolism of clinically used drugs [4]. Furthermore, in a review of drugs that are frequently cited in ADR studies, 59\% were found to be metabolized by at least one enzyme that is known to have a genetic variant for poor metabolism [5]. Updated information can be found on the Human CYP allele nomenclature website (http://www.cypalleles.ki.se/). Polymorphic enzymes (in particular CYP2C9, CYP2C19 and CYP2D6) mediate the metabolism of about $40-45 \%$ of all drugs on the market. Mutations in the CYP genes can produce enzymes with abolished, reduced, altered or increased enzyme activity, leading to four major phenotypes: poor metabolizers (PMs), who lack functional enzyme; intermediate metabolizers (IMs), who are heterozygous for a defect allele or carry two alleles that cause reduced activity; extensive metabolizers (EMs), who have two normal alleles; ultrarapid metabolizers (UMs), who carry more than two functional gene copies.

Since its independent discovery in three different laboratories in the 1970s, there can be no doubt that the CYP2D6 polymorphism (debrisoquine/sparteine hydroxylation polymorphism) is by far the most extensively studied polymorphically expressed drug-metabolizing enzyme in humans. The CYP2D6 gene, which is localized on chromosome 22q13.1, has turned out to be extremely polymorphic, with approximately 100 allelic variants described to date. Three major mutant alleles, CYP2D6*3, $* 4$ and $* 5$, are associated with the PM phenotype. In Western Europe, the incidence of PMs is 7\%. The term UM was coined after first disclosure by Johansson et al. [6], of an inherited duplication/multiduplication of an active gene encoding a drug-metabolizing enzyme in two Swedish families, with up to 12 extra CYP2D6 gene copies in the subjects who possessed very high CYP2D6 (debrisoquine) metabolic activity [6]. Subsequent investigations of the frequencies of UMs in different populations revealed a European-African (north-south) gradient in the incidence of CYP2D6 gene duplication. UMs are uncommon $(1-3 \%)$ in Northern Europe and Germany, but are preferentially distributed among populations in the Mediterranean area, where $10 \%$ of the populations of Portugal, Spain, Italy and Turkey carry alleles with multiple CYP2D6 gen copies. The frequency of UMs is as high as 29\% in Ethiopians and 20\% in Saudi Arabians.

Estimates reveal that between 20 and $25 \%$ of all drugs in clinical use are metabolized at least in part by CYP2D6. Subjects with multiple gene copies will metabolize drugs more rapidly, and therapeutic plasma levels will not be achieved at ordinary drug dosages. Individuals lacking functional CYP2D6 genes metabolize selective CYP2D6 substrates at a lower rate, and the risk for ADRs is higher [7]. It would therefore be ideal if practicing physicians could use genetic tests - before a pharmaceutical was ever administered - to optimize a patient's chance of significantly benefitting from drug treatment and to prevent most, if not all, ADRs. Both consequences of such an approach would result in lowering the overall expenditure for health care $[8,9]$.

Nevertheless, the sources of variability in drug response are multifactorial and apart from genetics, other factors, such as pathophysiology, environment, drug-drug interactions, drug allergies, medication errors and poor compliance, may have a profound impact on drug pharmacokinetics and/or pharmacodynamics, thereby affecting the therapeutic outcome tremendously. Thus, one should keep in mind that the majority of drug-response phenotypes are result from the nature versus nurture combination of genetic, environmental, and gene-environment interactions [10]. This issue highlights the role of therapeutic drug monitoring (TDM) as a potentially useful and complementary approach of pharmacogenetic testing for making a therapeutic decision and guiding individual drug dosing.

This review discusses a number of examples of the clinical applicability and usefulness of pharmacogenetic testing, either alone or in combination with TDM methods, for optimally guiding drug therapy. The aim was not to present an exhaustive description of pharmacogenetic and TDM methods, but to consider some important achievements, with emphasis on the pharmacogenetics of drug-metabolizing enzymes. In fact, the most frequently used categories of drugs with pharmacogenetic testing information in drug labels are those whose pharmacokinetics are affected by variations in CYP enzymes [11]. The drugs discussed here were selected on the basis of drug labelling-containing pharmacogenetic information and/or TDM recommendations.

\section{General considerations on pharmacogenetic testing and TDM}

The rapid development in our understanding of the genetic basis behind interindividual differences in drug response 
has been the result of two interwoven processes: human genome sequencing and the development of new technologies enabling automated and efficient genetic testing. One manner by which pharmacogenetic knowledge can be translated into routine clinical practice is by the establishment of guidelines and support from regulatory agencies. In fact, the pharmacogenetic revolution prompted the European Medicines Agency (EMEA) to establish in 2001 (formalized in 2005) the Pharmacogenetics (since 2008, Pharmacogenomics) Working Party (PGWP) group. It is a permanent and multidisciplinary core group of up to 14 experts that provide recommendations to the EMEA's Committee for Medicinal Products for Human Use (CHMP) on all matters relating directly or indirectly to pharmacogenomics. Further details of the composition PGWP group and scheduled meetings are available at websites http:// www.ema.europa.eu/pdfs/human/pharmacogenetics/ pgwpmandate.pdf and http://www.ema.europa.eu/pdfs/ human/pharmacogenetics/pgwpworkprogramme.pdf.

In January 2005, the U.S. Food and Drug Administration (FDA) gave its approval to the first pharmacogenetic test, the AmpliChip CYP450 test [12]. Currently, pharmacogenetic information is contained in more than 200 drug labels in the USA, and a significant increase in labels containing such information has been observed over the last decade. The FDA encourages the collection of genetic information and has recently approved modifications to 58 drug labels that now contain pharmacogenetic information [13].

The list of clinically available pharmacogenetic biomarkers and relevant drugs for which they can predict drug response is given in Table 1. The labeling of drugs is performed in the context of available knowledge and applicable standards at the time the labeling process takes place, and it is updated as new information becomes available. In many cases, the identified drug labels provide pharmacogenomic information without recommending a specific action, and only a few labels recommend or require biomarker testing as a basis for reaching a therapeutic decision. Assumptions are made because several issues arise when pharmacogenetic testing becomes part of routine analyses in clinical practice.

A critical step to select pharmacogenetic biomarkers is to diagnose the genetic variants associated with an increased risk for drug toxicity or idiosyncratic reactions and those variants that are associated with therapeutic failure [10]. However, it may take many years of study to identify genetic risk factors clinically relevant for drug pharmacokinetics and/or pharmacodynamics, and this delay impedes our ability to identify, evaluate and use genetics to optimize drug selection and dose. Moreover, drug approvals have only recently included more pharmacogenomic information and, consequently, still few pharmacogenomic biomarkers have the status of required or recommended (approximately $3 \%$ prevalence in the study by Frueh et al. [11]). These gaps need to be overcome to ensure that pharmacogenomic information will be directly applicable to patient care.

On the other hand, although it is obvious that a significant portion of the variability in response to many drugs can be attributed to genetic factors, it is also important to consider the nongenetic influences that have a profound impact on drug response. Thus, factors such as diet [14], drug interactions [15-17], adherence [18], age [19], organ function and disease $[20,21]$ are critical components of intra- and intersubject variability in drug response.

Thus, the effective design and interpretation of clinical studies that can simultaneously examine numerous contributory genetic and environmental aspects, while at the same time recognizing the degree to which environmental factors may be capable of obscuring genetic associations, are major challenges for the future.

It is known that underlying or coexisting conditions often influence the expression of many genes critical to drug disposition. For instance, tumor-associated inflammatory responses resulting in a downregulation of CYP3Amediated metabolism, but not genetic factors, have been found to contribute to the variability in drug clearance and toxicity of docetaxel in cancer patients [22].

Additionally, drug interactions are by far the most important factors to consider as sources of variability in drug response and the main contributory factors that explain why the drug metabolic genotype does not reflect the phenotype accurately, therefore limiting the usefulness of genotyping methods. This is an important health concern in psychiatry because psychiatric patients frequently require combinations of psychotropic drugs to treat comorbid psychiatric or somatic disorders, to control ADRs or to augment a medication effect [16, 17, 23-28]. Most psychotropic drugs are lipophilic agents extensively metabolized in the liver before excretion. These drugs undergo phase I oxidative reactions, and the mechanism of clinically relevant drug interactions normally involves the inhibition or induction of the activity of cytochrome P450 enzymes. In the broad sense, of unique importance is the capacity of the selective serotonin re-uptake inhibitors to inhibit the metabolic activity of human CYPs $[23,29,30]$. In this context, in psychiatry, TDM may provide a rational basis for optimal drug therapy and a suitable tool to assess the drug-related phenotype accurately [9, 31, 32].

TDM is based on the hypothesis that the concentration of a drug in the blood (plasma or serum) reflects the concentration at the target site better than the given dose. It is also is based on the assumption that there is a definable relationship between plasma drug concentration and clinical effects. TDM, as a pharmacogenetic testing approach, is a valid tool to phenotype the pharmacokinetics of a drug and individualize drug therapy, adjusting patient's dose requirements through the measurement and interpretation of drug concentrations. 
Table 1 List of clinically valid pharmacogenetic biomarkers and level of recommendation for related drugs in the context of FDA-approved drug labels

\begin{tabular}{|c|c|c|c|}
\hline Pharmacogenetic marker [106] & Representative drug & Disease & Test name $^{\mathrm{a}}$ \\
\hline CCR5 expression +++ & Maraviroc & HIV infection & Trofile \\
\hline$c-K I T$ expression + & Imatinib & Gastrointestinal stromal tumor & DakoCytomation c-Kit pharmDx \\
\hline $\begin{array}{l}C Y P 2 C 9 \text { variants; } \\
\text { VKORC1 variants }++\end{array}$ & Warfarin & Thromboembolism & $\begin{array}{l}\text { Verigene Warfarin Metabolism } \\
\text { Nucleic Acid Test }\end{array}$ \\
\hline CYP2C19 variants + & Voriconazole & Fungal infection & Roche Amplichip CYP450 test \\
\hline CYP2D6 variants + & Atomoxetine, fluoxetine & $\begin{array}{l}\text { Attention-deficit hyperactivity } \\
\text { disease, depression, OCD }\end{array}$ & Roche Amplichip CYP450 test \\
\hline$D P D$ deficiency + & Capecitabine, 5-FU & Colorectal cancer & TheraGuide 5-FU \\
\hline EGFR expression + & Erlotinib & Non-small-cell lung cancer & DakoCytomation EGFr pharmDx \\
\hline $\begin{array}{c}E G F R \text { expression and } \\
K-R A S \text { mutation }+++\end{array}$ & Cetuximab, panitumumab & Colorectal cancer & $\begin{array}{l}\text { DakoCytomation EGFr pharmDx } \\
\text { and Nucleotide sequencing-high- } \\
\text { resolution melting (HRM) analysis }\end{array}$ \\
\hline G6PDH deficiency + & Primaquine & Malaria & $\begin{array}{l}\text { Glucose-6-phosphate dehydrogenase } \\
\text { screening }\end{array}$ \\
\hline G6PDH deficiency ++ & Rasburicase & Hyperuricemia & $\begin{array}{l}\text { Glucose-6-phosphate dehydrogenase } \\
\text { screening }\end{array}$ \\
\hline$H E R 2 / N E U$ overexpression +++ & Trastuzumab & Breast cancer & Herceptest \\
\hline HLA-B* $1502^{b}++$ & Carbamazepine, phenytoin & Epilepsy & HLA typing \\
\hline HLA-B*5701 ++ & Abacavir & HIV infection & HLA typing \\
\hline$N A T$ variants + & Isoniazid, rifampin & Tuberculosis & Genelex \\
\hline Ph1 chromosome + & Busulfan & Chronic myelogenous leukemia & $\mathrm{BCR} / \mathrm{ABL}$ test \\
\hline Ph1 chromosome +++ & Dasatinib, imatinib & Acute lymphoblastic leukemia & $\mathrm{BCR} / \mathrm{ABL}$ test \\
\hline$P M L / R A R$ gene expression + & Tretinoin & Acute promyelocystic leukemia & $\begin{array}{l}\mathrm{PML} / \mathrm{RAR} \alpha \text { quantitative } \\
\text { real-time PCR }\end{array}$ \\
\hline$T P M T$ variants ++ & Azathioprine, 6-MP, thioguanine & Acute lymphocytic leukemia & Prometheus TPMT Genetics \\
\hline UGT1A1 variants + & Nilotinib & Chronic myelogenous leukemia & Invader UGT1A1 Molecular Assay \\
\hline UGT1A1 variants ++ & Irinotecan & Colorectal cancer & Invader UGT1A1 Molecular Assay \\
\hline
\end{tabular}

5-FU, 5-Fluorouracil; 6-MP, 6-mercaptopurine; ABL, Abelson; BCR, breakpoint cluster region; CCR, chemokine (C-C motif) receptor; c-KIT, vkit Hardy-Zuckerman 4 feline sarcoma viral oncogene homolog; CYP2C9, cytochrome 2C9; CYP2C19, cytochrome 2C19; CYP2D6, cytochrome 2D6; DPD, dihydropyrimidine dehydrogenase; EGFR, epidermal growth factor receptor; FDA, U.S. Food and Drug Administration; G6PDH, glucose-6-phosphate dehydrogenase; HER, human epidermal growth factor receptor; HLA, human leukocyte antigen; NAT, $N$-acetyltransferase; OCD, obsessive-compulsive disorders; Ph1, Philadelphia; PML/RAR, retinoic acid receptor; TPMT, thiopurine S-methyltransferase; UGT1A1, uridine diphosphate glucuronosyltransferase 1A1; VKORC1, vitamin K epoxide reductase complex subunit 1.

${ }^{a}$ The names of specific pharmacogenetic tests are provided for information purposes only as examples of available tests and do not constitute an endorsement of any particular test or vendor

${ }^{\mathrm{b}}$ For patients with an Asian ancestry. FDA classification: +, for information only; ++, recommended; +++, required

TDM methodological approaches have developed in three phases starting, more than 40 years ago, with conventional TDM of psychotropic drugs as an useful model for exploring genetic and environmental factors involved in interindividual variability in drug metabolism $[33$, 34]. During the 1990s, TDM was supplemented by pharmacogenetic methods for phenotyping and later improved by the addition of genotyping methods. In 2004, the first consensus guidelines on the indications for TDM and recommended plasma levels of antidepressants and antipsychotic drugs were published by an interdisciplinary TDM group of the Arbeitsgemeinschaft fur Neuropsychopharmakologie und Pharmakopsychiatrie (AGNP) $[35,36]$.
These guidelines classified the scientific strength of the recommendations for TDM of drugs into five groups, namely, (1) strongly recommended, (2) recommended, (3) useful, (4) probably useful and (5) not recommended. Consensus guidelines also exist for the determination of lithium, anticancer drugs, immunosuppressant drugs, antiretroviral drugs and certain antibiotics, among others [37-41].

Based upon the evidence that disentangling environmental effects from genetic influence as sources of variability in drug response is not always possible, the combined use of classical TDM (as a phenotyping approach) and genotyping of drug metabolic capacity is currently considered to be the 
most sophisticated way to individualize the dosage of several drugs for which the effects are difficult to evaluate $[9,38,41-43]$.

\section{Clinical applicability of pharmacogenetic testing and TDM in the context of pharmacogenetic information added to drug labels}

Immunosupressant drugs

\section{Tacrolimus}

The calcineurin inhibitor tacrolimus is highly effective in preventing acute rejection after solid organ transplantation, including that of the liver and kidney. Since calcineurin inhibitors in general show high inter- and intrasubject variability in pharmacokinetics while displaying a narrow therapeutic index, the influence of genetic polymorphisms in the development of toxicity has also been explored.

Tacrolimus is extensively metabolized by CYP3A isoforms [44], which are encoded by genes with known polymorphisms. Of these, the $C Y P 3 A 5^{*} 3$ allelic variant (present in most Caucasian individuals) produces a truncated protein with no activity. Therefore, only carriers of at least one wild-type (WT) allele, CYP $3 A 5^{*} 1$, are able to express functional protein.

In 2003, two studies in renal transplant recipients of Caucasian origin $[45,46]$ demonstrated that patients with the CYP $3 A 5^{*} 3 / * 3$ genotype require less tacrolimus to reach target predose concentrations than those with the CYP $3 A 5^{*} 1 * 1$ genotype (CYP3A5 expressors). Later studies in different populations, both in kidney and liver transplant recipients, further confirmed these initial findings [47-50]. For renal transplant recipients receiving tacrolimus, practitioners can expect $C Y P 3 A 5^{*} 1$ allele carriers to have a $25-45 \%$ greater tacrolimus clearance than $C Y P 3 A 5^{*} 3$ homozygotes, with proportional dosing needed to maintain adequate immunosuppression [51].

Tacrolimus is also a substrate for the drug transporter Pglycoprotein (Pgp), encoded by the $A B C B 1$ gene. In consequence, the effect of $A B C B 1$ polymorphisms on tacrolimus pharmacokinetics and pharmacodynamics has been extensively studied, although with contradictory results [47, 52-54]. The study by Elens et al. [55] in 150 liver donors helped to clarify this situation, as their results show how $A B C B 1$ single nucleotide polymorphisms (SNPs) significantly influence tacrolimus hepatic concentrations, but not blood levels. As tacrolimus hepatic concentrations have been significantly related to the graft outcome, the authors suggested that it might be interesting to genotype livers donors for $A B C B 1$ polymorphisms to better individualize immunosupression therapy with tacrolimus.
However, the genotype combinations CYP $3 A 4 * 1 /$ $C Y P 3 A 5^{*} 1$ and $C Y P 3 A 4^{*} 1 B / C Y P 3 A 5^{*} 1$ have been significantly more frequently associated with tacrolimus-related nephrotoxicity than the $C Y P 3 A 4^{*} 1 / C Y P 3 A 5^{*} 3$ genotype, which is the most common in Caucasians [56]. One study failed to find an association between $A B C B 1$ polymorphisms and adverse effects [56]; however, in an earlier published report on the use of cyclosporine, by Hauser et al. [57] suggested that it is the $A B C B 1$ genotype of the donor-and not of the recipient-that is the main risk factor for the development of nephrotoxicity, and such could also be the case of tacrolimus.

Taken as a whole, these reports support the concept that pharmacogenetic testing could be useful when administering tacrolimus in routine clinical practice. Indeed, this has been very recently demonstrated by a large prospective study that may be considered a proof of concept. In this study, kidney transplant recipients were randomly assigned to receive tacrolimus either according to CYP $3 A 5$ genotype or according to the standard daily regimen. Pharmacogenetic adaptation of the daily dose of tacrolimus allowed individualization of the first doses administered and was associated with a higher proportion of patients achieving target trough concentration $\left(\mathrm{C}_{0}\right)$ at an earlier time point after the transplant, fewer tacrolimus dose modifications, and a shorter delay in reaching target $\mathrm{C}_{0}$ level [58].

Finally, since inadequate immunosuppression is linked to graft rejection and because high tacrolimus plasma levels have been associated to serious adverse effects, TDM may be helpful in the first stages of the treatment in determining an appropriate starting dosage, rapidly achieving adequate immunosuppression through controlling the evolution of tacrolimus levels and ultimately improving the outcome of renal transplantation (Table 2) [59].

\section{Thiopurines}

As classic prodrugs, thiopurines (azathioprine, 6mercaptopurine and 6-thioguanine) require bioactivation by a multistep pathway to form thioguanine nucleotides (6TGNs), which are thought to be responsible for their pharmacological effect but also for bone marrow toxicity. These active (and toxic) metabolites are inactivated by thiopurine $S$-methyltransferase (TPMT) [60], whose genetic locus is subject to genetic polymorphisms associated with decreased enzyme activity. Heterozygous individuals (7$15 \%$ of Caucasians) show intermediate TPMT activity, whereas WT homozygous subjects, accounting for $85-90 \%$ of the population, display full TPMT activity. Interestingly, approximately one in 300 individuals is a homozygous mutant with low or negligible detoxification activity. If these latter patients are treated with standard doses of thiopurine drugs, they are at higher risk of potentially fatal 
Table 2 List of representative drugs for which pharmacogenetic biomarkers and/or therapeutic drug monitoring have demonstrated usefulness for improving drug efficacy and/ or avoiding toxicity

For abbreviations, refer to the footnotes of Table 1

${ }^{\mathrm{a}}$ For patients with an Asian ancestry

${ }^{b}$ the genetic biomarker is not in the list of FDA-approved drug labels

${ }^{\mathrm{c}}$ no not used routinely

\begin{tabular}{|c|c|c|}
\hline Drug & Genomic biomarker & Availability of TDM assay \\
\hline Abacavir & HLA-B*5701 & $\mathrm{Yes}^{\mathrm{c}}$ \\
\hline Antidepressants (tricyclic) & $C Y P 2 D 6$ variants & Yes \\
\hline Antipsychotics (typical) & $C Y P 2 D 6$ variants & Yes \\
\hline Azathioprine & TPMT & Yes \\
\hline Carbamazepine & HLA-B $* 1502^{\mathrm{a}}$ & Yes \\
\hline Cetuximab & $E G F R$ expression and $K-R A S$ & $\mathrm{Yes}^{\mathrm{c}}$ \\
\hline Dasatinib & Ph1 chromosome & $\mathrm{Yes}^{\mathrm{c}}$ \\
\hline Efavirenz & $C Y P 2 B 6^{*} \sigma^{\mathrm{b}}$ & $\mathrm{Yes}^{\mathrm{c}}$ \\
\hline Imatinib & Ph1 chromosome, $c$-KIT expression & $\mathrm{Yes}^{\mathrm{c}}$ \\
\hline Irinotecan & $\mathrm{UGT} 1 \mathrm{~A} 1 * 28$ & No \\
\hline Maraviroc & CCR5 expression & $\mathrm{Yes}^{\mathrm{c}}$ \\
\hline 6-Mercaptopurine & ТРMT & Yes \\
\hline Panitumumab & $E G F R$ expression and $K-R A S$ & $\mathrm{Yes}^{\mathrm{c}}$ \\
\hline Phenytoin & $C Y P 2 C 9$ variants, HLA-B* $1502^{\mathrm{a}}$ & Yes \\
\hline Tacrolimus & $C Y P 3 A$ variants & Yes \\
\hline Tamoxifen & $C Y P 2 D 6$ variants & $\mathrm{Yes}^{\mathrm{c}}$ \\
\hline Trastuzumab & $H E R 2 / N E U$ overexpression & No \\
\hline Warfarin & $C Y P 2 C 9$ variants; $V K O R C 1$ variants & No \\
\hline
\end{tabular}

haematological toxicity [61]. On the contrary, patients with very high TPMT activity are more likely to be non-responders to treatment with azathioprine or 6-mercaptopurine [62]. In addition, the elevated TPMT activity may also translate into hepatotoxicity due to the formation of metabolites other than 6-TGNs, such as 6-methylmercaptopurine ribonucleotides (6MMPN) [63, 64].

In several independent studies, the determination of the TPMT genotype has shown excellent concordance with the TPMT phenotype $[65,66]$. Even though many TPMT allelic variants have been identified to date, up to $95 \%$ of the defective TPMT activity can be explained by just the most frequent mutant alleles, namely $T P M T^{*} 2, T P M T^{*} 3 A$ and TPMT*3C [67].

It is of note that the fact that patients with low TPMT activity often develop myelossuppression does not imply the opposite, i.e., that every patient with these symptoms has low TPMT activity. For example, McGovern et al. [68] found that only one out of 22 patients who were intolerant to azathioprine had an intermediate TPMT activity, with the remaining 21 patients having normal TPMT activities. Another limitation to the use of genetic tests with thiopurine drugs was recently highlighted by Winter et al. [69], who suggested that measurement of TPMT phenotype may be superior to genotype in predicting severe myelossuppression. The results of their study showed that a moderate reduction of erythrocyte TPMT activity in heterozygotes was not associated with toxicity, while very low TPMT activity in one heterozygote caused severe myelosuppression. The authors concluded that this would have been predicted by measuring TPMT activity, but not by genotyping. In any case, the FDA has approved safety labelling changes for thiopurine drugs, alerting prescribers to the possibility of TPMT status measurement to reduce the risk of developing life-threatening myelosuppression in patients found to be TPMT deficient (Table 1). Despite a certain controversy, raised mostly because the frequency of TPMT-deficient individuals is as low as $0.3 \%$ and because WT patients may also develop myelotoxicity [70], most of the pharmacoeconomic studies carried out to date seem to favour the prospective TPMT activity [71-74].

The assessment of a normal TPMT genotype does not exclude the usefulness of TDM during patient follow-up as a complementary tool to optimize therapy with azathioprine. Indeed, routine measurements of 6-TGN and 6MMPN metabolites are perhaps more important than genotyping when choosing the appropriate course of therapy for nonresponders and patients suspected of incomplete compliance [42].

Anticancer drugs

In oncology, new genetic technologies are characterizing patients biologically, with the aim to drive more effective cancer treatment and more efficient cancer drug development.

\section{Cetuximab/panitumumab}

The epidermal growth factor receptor (EGFR) is a receptor tyrosine kinase of the ErbB family that is abnormally activated in many epithelial tumors. Several mechanisms 
lead to the receptor's aberrant activation that is observed in cancer, including receptor overexpression, mutation, liganddependent receptor dimerization and ligand-independent activation. Two classes of anti-EGFR agents are currently approved for the treatment of patients with cancer. First, cetuximab and panitumab are two monoclonal antibodies directed at the extracellular domain of the receptor; secondly, dasatinib and imatinib are oral, low-molecularweight, adenosine triphosphate-competitive inhibitors of the receptor's tyrosine kinase.

Anti-EGFR monoclonal antibodies have demonstrated activity in the therapy of advanced colorectal carcinoma and in a variety of epithelial tumor types, including head and neck cancers and non-small cell lung cancer. Major efforts are focusing on identifying molecular markers that can predict those patients more likely to respond to antiEGFR therapy [75].

The concept of basing clinical decisions regarding cancer patient management with anticancer drugs on genetic testing results is controversial. Some authors have stated that colorectal cancer patients with EGFR-negative tumors have the potential to respond to cetuximab-based therapies. EGFR analysis by current immunohistochemistry techniques does not seem to have a predictive value, and the selection or exclusion of patients for cetuximab therapy does not seem to be warranted. According to these authors' statements, no patient should be denied treatment with an EGFR-targeting agent solely on the basis of a negative EGFR immunohistochemistry test result, and no patient should be given anti-EGFR therapy simply on the basis of a positive or strongly positive EGFR test result $[76,77]$.

A recent re-evaluation of clinical data across seven randomized clinical trials of patients with metastatic colorectal cancer has prompted the FDA to modify the usage label of cetuximab and panitumab. Accordingly, both drugs should be prescribed only to individuals whose tumours harbour the non-mutated or WT form of the $K$ $R A S$ gene (Table 1) as this therapy had not shown a treatment benefit for patients carrying the $K-R A S$ mutations in codon 12 or 13 [78].

Although part of the interindividual differences in response to monoclonal antibodies may be explained by interindividual variability in pharmacokinetics, TDM of monoclonal antibodies is not carried out routinely. Therefore, an assay measuring the concentrations of these drugs may be useful for the interpretation and dose individualization of these drugs (Table 2) [79].

\section{Dasatinib/imatinib}

Chronic myeloid leukemia (CML) is characterized by the presence of the Philadelphia $(\mathrm{Ph})$ chromosome, which results from a reciprocal translocation between the long arms of chromosomes 9 and $22 \mathrm{t}(9 ; 22)(\mathrm{q} 34 ; \mathrm{q} 11)$. This translocation creates two new genes, BCR-ABL on the $22 \mathrm{q}-$ $(\mathrm{Ph})$ chromosome and the reciprocal ABL-BCR on $9 \mathrm{q}-$. The $B C R-A B L$ gene encodes for a $210-\mathrm{kDa}$ protein with deregulated tyrosine kinase (TK) activity, which is crucial for malignant transformation in CML. The recognition of the $B C R-A B L$ gene and corresponding protein led to the synthesis of small-molecule drugs designed to interfere with BCR-ABL. The rational development of drugs targeting BCR-ABL has significantly improved the treatment of CML. Imatinib (a BCR-ABL tyrosine kinase inhibitor) produces haematological and cytogenetic remissions across all phases of CML and is the current standard of care. Imatinib resistance occurs in a significant proportion of patients, and the mechanisms of resistance include BCRABL mutations and activation of alternate oncogenic pathways. Dasatinib is a novel, potent, multi-targeted oral kinase inhibitor. Preclinical and clinical investigations have demonstrated that dasatinib effectively overcomes imatinib resistance and has further improved the treatment of CML. Dasatinib was approved by the FDA for use in Ph-positive leukaemias in patients who are resistant or intolerant to imatinib (Table 1) [80].

TDM of the selective inhibitors of tyrosine kinases dasatinib and imatinib may contribute to filling the current knowledge gaps in the pharmacokinetics/pharmacodynamics relationships of the drugs and better define their therapeutic ranges in different patient populations [81].

\section{Irinotecan}

Irinotecan has advanced in the last years to become an important cytostatic drug in the treatment of colorectal carcinoma, particularly in those patients refractory to 5fluoruracil. It is activated in hepatocytes and tumour cells to SN-38, a potent topoisomerase I inhibitor, which is in turn conjugated (detoxified) by UDP glucuronosyltransferase 1A1 (UGT1A1) to SN-38 glucuronide. Gupta and coworkers [82] first reported that the extent of this glucuronidation is inversely correlated with gastrointestinal toxicity and suggested that the variability in this detoxification step is of genetic origin. Shortly after these findings were made known, a functional polymorphism was identified in the $U G T 1 A 1$ gene $\left(U G T 1 A 1^{*} 28\right)$; this allelic variant consisted of an extra TA repeat ( 7 versus 6 ) in the promoter sequence and was associated to a decreased glucuronidation rate [83, 84]. In accordance with the described effect of this polymorphism, carriers of the $* 28$ allele showed a lower rate of SN-38 glucuronidation and were more susceptible to irinotecan-induced toxicity [85]. Subsequent studies revealed a relative risk of 9.3 for grade 4 neutropenia in carriers of the homozygous genotype (7/7) versus the rest of the patients [86]. This $7 / 7$ genotype was also found to be 
prevalent in patients with irinotecan grade $3 / 4$ diarrhea and neutropenia [87]. There may be other polymorphisms in the coding regions of $U G T 1 A 1$, which may or may not be in linkage disequilibrium with $U G T 1 A 1^{*} 28$ and which could be contributing to the variability in the glucuronidation of the SN-38 metabolite. For example, UGT1A1*6 and*27 alleles as well as combinations with other SNPs are also candidates to be tested for more individualized irinotecan chemotherapy, especially among the Asian population where these allele frequencies are higher [88-91].

These and other similar findings led the FDA in 2005 to amend the package insert for irinotecan to include a recommendation, but not a requirement, to test for the *28 UGT1A1 variant to predict those at risk for neutropenia (Table 1) [13]. In response to these changes, a number of commercially available assays have been developed to determine the presence of this polymorphism. As suggested by the above-mentioned studies, these tests should be used by clinicians to identify patients at risk of suffering severe toxicity who must therefore be treated with lower starting irinotecan doses.

The determination of $U G T 1 A 1 * 28$ seems to be an example of practical pharmacogenetics that may be routinely applied. However, the work is far from being over because UGTIA1 genetic testing may be limited in its general applicability in diverse populations, such as African, Americans and Hispanics, that are currently underrepresented in pharmacogenetic studies [13]. Secondly, a relatively inexpensive biomarker, total serum bilirubin, is available as a clinical predictor of liver function and as a surrogate marker of UGT1A1 enzyme function and severe neutropenia before the administration of irinotecan. Third, the test does not include specific dosing recommendations and instructions on how to interpret the results [13].

Additional strategies have been suggested, and these include the standardization of safe and efficacious doses for the $6 / 6,6 / 7$ and $7 / 7$ genotypes, the determination of whether resistance to treatment is also associated to this genetic variability, the inclusion of other minor genotypes, such as those consisting of 5 or 8 repeats, or the identification of other key polymorphisms in nonCaucasian populations [92].

\section{Tamoxifen}

Tamoxifen has been the most important therapeutic agent for the treatment of estrogen receptor (ER)-positive patients with breast cancer for the past three decades. Several lines of evidence indicate that most of the tamoxifen antiproliferative effects in breast cancer models are mediated by the metabolites 4-hydroxytamoxifen and endoxifen, with a different mode of action for endoxifen being suggested [93]. The drug's activation is mainly mediated by the polymorphic enzyme CYP2D6, which catalyses the conversion of tamoxifen into the active metabolite endoxifen [94]. The impact of low-activity CYP2D6 genotypes on tamoxifen metabolism has been examined, and reduced endoxifen levels have been found $[95,96]$. These results prompted Goetz et al. [97] to perform a study in 223 women with early-stage ER-positive breast cancers treated with tamoxifen; the results showed that patients homozygous for the CYP2D6 *4*4 genotype (CYP2D6 PMs) had a worse recurrence-free time and disease-free survival but a lower incidence of hot flashes compared with women with one or zero *4 alleles, as they would have lower levels of the active metabolite endoxifen. On the contrary, a study by Wegman et al. [98] reported that *4/4 carriers had a better disease-free survival than WT patients, although the difference did not reach statistical significance and only the $C Y P 2 D 6^{*} 4$ variant allele was analyzed.

A later study demonstrated that the inclusion of concomitant use of CYP2D6 inhibitors in the analysis strengthened the significance of the association between low CYP2D6 enzyme activity (either by genotype or drug interaction) and worse breast cancer prognosis (hazard ratio for relapse in $\mathrm{PMs}=3.12$ ) [99]. Thus, knowledge of the pharmacogenetic variation known to abrogate CYP2D6 enzyme activity may provide a means by which the hormonal therapy of breast cancer can be individualized [100]. Schroth et al. [101] recently demonstrated, for the first time, an association between CYP2D6 genetics and clinical outcome of tamoxifen. Their study was a retrospective analysis that included a large cohort of 1,325 breast cancer patients treated with adjuvant tamoxifen for early-stage disease. There was a variant-allele dosedependent increase of the incidence of recurrence and death events among CYP2D6 phenotypes. Patients lacking CYP2D6 enzyme function (PMs) had the highest rates, with an almost twofold increased risk of developing breast cancer recurrence compared with patients with two functional CYP2D6 alleles (EMs). The effect was lower in patients with intermediate impairment of enzyme function (heterozygous EMs/IMs), underscoring the primary role of CYP2D6-mediated tamoxifen activation to its active metabolite; (i.e., endoxifen [93]). The relationship between the number of functional alleles and clinical outcome was further evident for CYP2D6 UMs (2.3\% of all patients) who accounted for the best tamoxifen outcome [101].

No indication for the use of the test has yet reached guideline status but, based on the findings mentioned above, the FDA is currently weighing the possibility of including a recommendation in the drug label on the use of CYP2D6 testing to improve clinical outcomes in postmenopausal women with ER-positive breast cancer who are CYP2D6 PMs. The availability of microarray hybridization methods, such as the AmpliChip [102], makes the rapid 
analysis of DNA for the genotyping of many different CYP2D6 genotypes possible, and the benefits of these tests are obvious for these patients.

Finally, further evaluation of TDM approaches is needed to determine whether the assessment of tamoxifen in plasma could be useful as a complementary tool for guiding drug dosage in breast cancer patients [103].

\section{Trastuzumab}

Trastuzumab is a recombinant humanized monoclonal antibody directed against human EPGR 2 (HER2), whose use as an adjuvant in chemotherapy has resulted in outstanding hazard ratios for breast cancer recurrence compared with chemotherapy alone [104, 105]. According to the FDA-approved drug label, detection of HER2 protein overexpression is necessary for the selection of patients suitable for receiving therapy with trastuzumab (Table 1) [106]. The downside to this discussion is that there is variable risk of trastuzumab-induced cardiotoxicity that depends mainly on the concomitant medication [107]. A recent report indicates that this cardiotoxicity may also be significantly associated to a polymorphism-generating valine instead of isoleucine at position 655 in the HER2 gene [108]. However, even though (1) it would be easy to genotype patients prior to starting trastuzamab therapy and (2) the adverse effect ADR is serious enough to justify the screening, the great antineoplastic efficacy shown by trastuzamab makes it difficult to predict whether these genetic tests will routinely be applied in the near future.

\section{Anticoagulant drugs}

\section{Warfarin}

Warfarin was first developed as a rodenticide in the 1940s and introduced into clinical practice in the 1950s. It was soon obvious that warfarin had an extraordinarily low therapeutic index and, hence, a tremendous variability in drug response, with patients at risk of excessive bleeding or therapeutic failure if the doses were too high or too low, respectively. In this regard, Pirmohamed and coworkers [109] identified warfarin as a causal agent in $10 \%$ of cases of all hospital admissions for ADRs in England.

The increasing interest in pharmacogenetics in the last years has made possible to identify genes that may have an impact on the outcome of warfarin treatment, the most widely used medicine for which a pharmacogenetic test has ever been proposed. The first gene to be studied was CYP2C9, which is responsible for the hepatic biotransformation of warfarin to inactive metabolites excreted in the urine. Two variant alleles, $C Y P 2 C 9 * 2$ and $C Y P 2 C 9 * 3$, both displaying frequencies of approximately $10 \%$ in Caucasians
[110], code for a defective enzyme that metabolizes warfarin, and both have been associated with an increased risk of bleeding during warfarin induction [111-114].

The other focus of those pharmacogenomic studies on anticoagulant treatment has been the vitamin $\mathrm{K}$ epoxide reductase complex subunit 1 (VKORC1) gene, whose product is inhibited by the warfarin mechanism of action. Rieder and coworkers [115] identified ten non-coding SNPs in this gene that could be used to infer different haplotypes. These results were reproduced by another research group [116], which showed that carriers of the VKORC1*2 haplotype require much lower warfarin doses than other patients, and they display a higher coefficient of variation of prothrombin time-International Normalized Ratio (INR), and a higher percentage of INR values outside the therapeutic interval.

In 2007, the FDA modified warfarin labelling to suggest, but not mandate, that clinicians consider warfarin pharmacogenetic testing before initiating therapy (Table 1). The $C Y P 2 C 9^{*} 2, C Y P 2 C 9^{*} 3$ and $V K O R C 1$ polymorphisms are the main SNPs considered for establishing an adequate warfarin dose. However, only about one third of all dosing variation is explained by the combined assessment of CYP2C19 and VKORC1 variants [117]. In order to effect further improvement of the initial warfarin dose, some authors [118] have suggested the inclusion of other SNPs, such as the non-common mutations in the VKORCl gene (e.g. Asp36Tyr polymorphism [119, 120]), polymorphisms in clotting factors II, VII and IX [121-123] or the C3435T polymorphism located in exon 26 of the $A B C B 1$ gene [124]. Other known clinical factors that can contribute to this high variability (up to a $30 \%$ ) are age, gender, body mass index and pharmacological interactions [125].

These genetic data have been added to clinical records to build algorithms as predictive models of adequate warfarin dose. A number of these algorithms can be found in the literature, and regression models that can explain over 50\% of the variability in the warfarin dose have been obtained [126-130]. It is of note that one of these studies reported an impressive accuracy $\left(R^{2}\right.$ value of $\left.79 \%\right)$ in estimating the warfarin dose [131].

However, these algorithms have a number of limitations. For example, they are usually developed for inpatients with accessible INR daily monitoring data, whereas many patients begin the anticoagulant therapy in an outpatient setting. Although several studies have confirmed that warfarin can be used safely in older people ( $>75$ years) who have previously been free from significant adverse effects ADRs, careful monitoring of the INR would appear to be critical [19]. Furthermore, as age is an important factor to consider for warfarin dosing $[128,132,133]$, it may be difficult to apply algorithms created for middle-aged patients to elderly subjects, the usual recipients of the drug. 
In contrast, the use of a pharmacogenetic algorithm for estimating the appropriate initial dose of warfarin appears to be a valuable tool in the $46.2 \%$ of the population that requires $\leq 21 \mathrm{mg}$ warfarin per week or $\geq 49 \mathrm{mg}$ per week for therapeutic anticoagulation [134]. The investigation of a multiple regression model in the largest prospective warfarin-treated cohort to date, using the predictors CYP2C9, VKORC1, age, sex and drug interactions, explained $59 \%$ of the variance in warfarin dose, supporting genetic forecasting through the initiation of warfarin guided by pharmacogenetics to improve clinical outcome [130]. In agreement with this, a genome-wide association study in a large sample size of 1,053 Swedish subjects, sufficiently powered $(80 \%)$ to detect genome-wide significance and applying multiple regression to adjust for known influences on warfarin dose, confirmed the role of VKORC1, CYP2C9 and $C Y P 4 F 2$ as principal genetic determinants of warfarin dose [135].

At the present time, dose adjustment of warfarin through INR monitoring and other clinical factors that influence warfarin dosing is receiving the most attention [117] but, fortunately, warfarin pharmacogenetic testing is commercially available (Table 1). The results from these tests have widely demonstrated their ability to help predict starting and maintenance doses.

\section{Anti-human immunodeficiency virus drugs}

\section{Abacavir}

The guanosine reverse-transcriptase inhibitor abacavir is an important antiretroviral treatment against infection with the human immunodeficiency virus (HIV) and has been used by almost 1 million patients infected with HIV during the past decade [136]. The case of abacavir is the paradigm of the utility of pharmacogenetic analyses in HIV therapy.

In white populations, hypersensitivity reactions (HSRs) can be a major problem when implementing an antiretroviral drug treatment in HIV-infected patients. Thus, 5-8\% of patients that are administered abacavir develop a potentially life-threatening drug hypersensitivity reaction (HSR) characterized by fever, rash and symptoms in the gastrointestinal tract, other organ systems, or both within 6 weeks of initiating therapy $[137,138]$.

The publication of reports containing evidence of familiar predisposition and decreased frequency of hypersensitivity reactions (HSRs) in subjects of African origin was the first indication of the involvement of genetic factors in determining the susceptibility to abacavir hypersensitivity. These initial studies led to the identification in 2002 of the $H L A-B^{*} 5701$ polymorphism in the human leukocyte antigene $(H L A)$ gene as a predictive factor of abacavirinduced hypersensitivity in Caucasians and Hispanics
[139-142]. For unknown reasons, the relationship between HLA-B alleles and hypersensitivity reactions (HSRs) is less clear within black populations. Furthermore, in Asian populations, the frequency of $H L A-B^{*} 5701$ is very low, thus restricting the usefulness of this pharmacogenetic biomarker mainly to whites [142]. This genetic marker is sufficient to stratify susceptibility to abacavir hypersensitivity reactions (HSRs) into categories of low-risk $(<1 \%)$ and high-risk $(>70 \%)$ patients according to the absence or presence of the HLA-B*5701 allele, respectively [143]. This variant allele-hypersensitivity reaction (HSR) association seems to be even stronger when the M493T polymorphism in the Hsp70-Hom gene is present in combination with $H L A-B^{*} 5701$. An Australian group reported that this combination was found in $94.4 \%$ of hypersensitivity reaction (HSR) cases and only in $0.4 \%$ of controls. These data indicate that the concurrence of $H L A-B^{*} 5701$ and Hsp70-Hom M493T alleles is necessary for the development of abacavir hypersensitivity [144].

It has been possible to apply these findings to clinical practice (Table 1). For example, the implementation of prospective $H L A-B^{*} 5701$ genetic screening was first adopted in Western Australia and has had a critical impact in reducing abacavir-induced hypersensitivity reactions (HSRs) [145]. Moreover, based on their study of 561 abacavir-naive patients of different ethnicities in the UK, the authors concluded that the implementation of pretreatment genetic screenings was able to reduce abacavir HSRs to $0.5 \%$ from the $6.2 \%$ observed in a cohort of 300 patients treated before the screenings [146]. In addition, the first results of PREDICT-1, a large-scale prospective international randomized blinded study, released at the "One Size Fits One-Treating the Individual" satellite symposium at the International AIDS Society Conference in Sydney (25 July 2007) further confirm these results, as they show a reduction of HSRs in abacavir-naive patients from 8 to $3.6 \%$ in those individuals subjected to prospective genetic screening.

The potential widespread use of these genetic tests is also dependant on cost-effectiveness. In this regard, Hughes and colleagues [141] showed that pre-treatment screening of $H L A-B^{*} 5701$ is a cost-effective tool to avoid abacavir HSRs in Caucasians and Hispanics, as these populations display an allelic frequency of at least $5 \%$. However, it is less cost-effective, as stated in the PREDICT-1 study early results, in individuals of African and Asian origin, as these populations seem to display a low allele frequency and, consequently, a reduced risk of developing HSRs [142, 147].

One more condition to be fulfilled for the genetic tests before they are routinely implemented in clinical practice is that they need to be practical and accurate, given the potential fatal effects of administering abacavir to a patient 
wrongly typed as $H L A-B^{*} 5701$-negative. A study by Hammond et al. [148] tested the proficiency of $H L A$ $B * 5701$ typing among laboratories using sequence-specific primer PCR and concluded that the participating HIV testing laboratories are currently offering effective primary screening to identify individuals at high risk of abacavir HSRs.

In summary, it is clear that pharmacogenetic screening of the $H L A-B^{*} 5701$ allele appears to be an effective pharmacogenetic test in white populations, with a high sensitivity and modest specificity. It is also an accurate and costeffective technique that can significantly improve abacavir therapy if included in the clinical routine. Its costeffectiveness in populations other than Caucasian and Hispanics has yet to be determined in large-scale prospective studies such as PREDICT-1 and SHAPE.

To achieve optimal drug concentrations for viral suppression and avoidance of drug toxicity, the monitoring of drug levels has been considered to be essential [149]. However, there is currently no consensus on the significance of TDM in the management of HIV infection. However, despite a large variation of anti-HIV drug plasma concentrations, single-measurement TDM seems to be a sufficient approach for the routine assessment of the majority of patients [150].

\section{Maraviroc}

The concept of chemokine (C-C motif) receptor 5 (CCR5) antagonists introduces an additional molecular target. Due to its unique mode of action with exclusive activity against CCR5 tropic strains, viral tropism testing is mandatory before CCR5 antagonists are used in the clinic [151]. Maraviroc (MVR) is approved by the FDA for use in HIV-1 infected patients for combination antiretroviral treatment of adults infected with only CCR5-tropic HIV-1 who have evidence of viral replication and HIV-1 strains resistant to multiple antiretroviral agents [152]. Since a considerable percentage of late-stage HIV patients still bear CCR5-tropic viruses, the use of CCR5 antagonists appears to be promising in properly selected treatment-experienced patients [153].

Various methods for monitoring plasma concentrations of maraviroc have been reported, but these are not used routinely in HIV-infected patients for whom exposure, tolerance and adherence assessments are critical $[154,155]$.

\section{Efavirenz}

CYP2B6 participates in the metabolism of important therapeutic drugs, such as the non-nucleoside reverse transcriptase inhibitors efavirenz and nevirapine, both of which are used in the treatment of HIV infection [156].
There is a good understanding of the genetic variation of CYP2B6 that allows the prediction of the pharmacokinetics of efavirenz [50, 156, 157]. In contrast, there is no consensus on the association of pharmacokinetics and efavirenz neuropsychological toxicity. However, some individuals that present neuropsychological toxicity may benefit from dose reduction [38]. CYP $2 B 6^{*} 6$ is the most common diminished-function allele across human populations and is associated to high plasma levels and central nervous system adverse effects (ADRs) [156, 158]. A study by Nyakutira et al. [159] showed a high prevalence of $C Y P 2 B 6^{*} 6$ allelic variant and high plasma efavirenz levels $(50 \%$ of the participants above threshold of $4 \mathrm{mg} / \mathrm{l})$. As much as $76 \%$ interindividual variability in efavirenz drug levels could not be explained by CYP2B6 genotyping [159], thereby raising the question of whether TDM or pharmacogenetic prediction should be used to optimize efavirenz drug therapy. Additionally, to reach maximal predictability, the analysis of multiple CYP2B6 alleles, TDM and possibly genotyping of accessory metabolic pathways of efavirenz would need to be considered [38, $150,160]$.

\section{Psychotropic drugs}

Large interindividual differences in drug response and, consequently, dosage requirement are well-known during treatment with psychotropic drugs. Antidepressant and antipsychotic drugs have a relatively narrow therapeutic range, particularly the older antidepressants, and clinicians have traditionally been concerned about the prevalence of ADRs with psychoactive drugs, which may sometimes mimic symptoms of the disease being treated. These patients may, therefore, require increased doses of medication to counteract the ADR symptoms that may result due to a higher risk of pharmacokinetics drug-drug interactions. These considerations make it difficult for psychiatric patients to comply with the therapeutic drug regimen. Therefore, as suggested by Dahl and Sjöqvist [161] a decade ago, drugs used for treating depression and psychosis fulfill many of the criteria for the combined use of TDM and pharmacogenetic methods for optimizing dosage schedules.

With a few exceptions, psychoactive drugs are extensively metabolized by enzymes in the cytochrome P450 family, of which the most important isoforms are CYP2D6, CYP2C19, CYP1A2 and CYP3A. As the result of the interplay between genetic and environmental factors, these enzymes show pronounced variability between individuals.

Most clinically useful antidepressants and antipsychotic drugs are metabolized by the polymorphic CYP2D6 enzyme. Indeed, the meta-analysis by Kirchheiner et al. [162] revealed that the dosage of about $50 \%$ of these drugs 
is greatly dependent on the CYP2D6 genotype. In this regard, the roles of the CYP1A2 and CYP3A metabolic activities are also increasingly acknowledged.

CYP2D6 phenotypes are important factors in patients taking tricyclic antidepressants (TCAs), venlafaxine, typical antipsychotics and risperidone $[12,162]$. The outcome of treatments with antidepressants newer than TCAs may also be affected by the presence of CYP2D6 variant alleles. For example, venlafaxine has been suggested to be a candidate for dosage individualization in the near future, as dysfunctional CYP2D6 alleles have been associated to serious adverse effects (ADRs) $[163,164]$. The next few years will determine whether CYP2D6 genotyping is beneficial for patients taking the new drugs aripiprazole, duloxetine and atomoxetine [12].

Another polymorphic enzyme, CYP2C19, is also involved in the metabolism of psychotropic drugs and, hence, the CYP2C19 PM phenotype is probably important in patients taking TCAs and perhaps citalopram, escitalopram and sertraline $[12,165]$.

Poor metabolizers have negligible CYP2D6 activity, either because they carry two defective CYP2D6 allelic variants (accounting for up to $7 \%$ of Caucasians) or because of CYP2D6 inhibition. Patients having three or more active CYP2D6 alleles (up to $29 \%$ in North African and Middle Eastern populations) are called CYP2D6 UMs, and they will probably show low plasma levels of CYP2D6 substrates and/or a lack of therapeutic response [6]. Therefore, it is also important to distinguish patients with extremely low plasma concentrations of psychotropic drugs that are metabolized by a duplicated CYP2D6 genetic variant from those not complying with the prescription.

Pharmacogenetic methods may be clinically useful in psychiatry to achieve optimal drug dosing. In a study of 100 consecutive psychiatric inpatients genotyped for CYP2D6 on admission, the number of side effects was higher and total duration of hospital stay longer among PM psychiatric patients treated with drugs metabolized by CYP2D6 [8]. In another study, Kawanishi et al. [166] found an over-representation of duplicated CYP2D6 genes $(10 \%)$ in patients with persistent depression (non-response) despite drug treatment, compared to a general Swedish population (1-2\%). Additionally, the cost of treating outliers, patients of the UM or PM CYP2D6, is US $\$ 4,000-6,000$ per year higher than those of the IM or EM phenotype [8]. In Italy and Spain, where gene duplication is common, one out of ten patients might require increased doses of CYP2D6 substrates [7].

In this context, the FDA completed in January 2005 its approval of the first pharmacogenetic test, the AmpliChip CYP450 Test, which assesses two polymorphic genes, namely, CYP2D6 and CYP2C19, involved in the metabolism of psychoactive drugs [12]. Genotype-based dose recommendations - not requirements - for antidepressants and antipsychotics have now been presented as a first step toward sub-population-specific dosages. Kirchheiner et al. [162] highlighted the importance of these two polymorphic genes in a review of pharmacogenetic data on 36 antidepressants, concluding that for 14 of these antidepressants, genetic variations at the CYP2D6 or CYP2C19 gene locus would require at least a doubling of the dose in EMs compared to PMs. However, the highly polymorphic nature of the CYP2D6 gene (to date, more than 60 allelic variants have been defined), and the resulting complexity of allele combinations make the prediction of phenotype based on genotype data particularly challenging [167].

Pharmacologic therapy of psychiatric disorders will likely be more effective once the molecular pathogenesis is known. However, very few schizophrenic patients share identical genomic causation. This is probably due to reduced fecundity, associated with severe mental disorders, such as autism, schizophrenia and mental retardation, leading to negative selection pressure on risk alleles that may explain, in part, why common variants have not been found that might confer risk to these disorders [168]. Thus, rare variants may account for a larger fraction of the overall genetic risk than previously assumed, thereby complicating efforts to personalize treatment regimens in these patients $[168,169]$. It was disappointing that the analysis of 25 known functional genetic variants of several metabolizing enzymes for five commonly used antipsychotic medications (olanzapine, quetiapine, risperidone, ziprasidone and perphenazine) produced no significant associations with drug dosing, safety, efficacy, tolerability, or risk for tardive dyskinesia, making predictive genetic testing for these drugs of little value in clinical settings [170].

The starting point for conventional TDM of tricyclic antidepressants was the early demonstration of marked interindividual differences in the plasma levels obtained at the fixed doses used in the mid-1960s, the genetic control of these levels and the concentration-dependent antidepressant effects that were demonstrated, particularly for nortriptyline, in controlled studies in several psychiatric clinics. At the time, it was considered that the clinical outcome could be improved and side effects avoided by selecting a dose resulting in an apparent therapeutic range of plasma concentrations [33, 34, 171]. In contrast to many drugs used in somatic diseases, the dosage of psychoactive drugs is difficult to optimize due to their slow onset of action, unpredictable clinical effects with many nonresponding patients, side effects mimicking the disease itself and interactions with other co-prescribed drugs.

Among the antidepressants, monitoring of essentially all tricyclics and venlafaxine is strongly recommended in view of their relatively well-established concentration-effect relationships. In the case of amitriptyline, clomipramine, 
imipramine and venlafaxine, the measurements of their active metabolites are also recommended. For the selective serotonin reuptake inhibitors, the two higher classifications for routine monitoring are not reached, but TDM is, nevertheless, judged to be useful in selected cases. Recently, much attention has been drawn to the TDM of fluoxetine and, in particular, to the analysis of fluoxetine enantiomers [172]. TDM is strongly recommended for the antipsychotics clozapine, fluphenazine, haloperidol and olanzapine [36]. Interestingly, all neuroleptics that are metabolized by the polymorphic CYP2D6 are considered to be strong TDM candidates (chlorpromazine, fluphenazine, haloperidol, perphenazine, risperidone and thioridazine). The combination of TDM and CYP2D6 genotyping seems to be particularly useful in verifying concentration-dependent ADRs due to poor metabolism and diagnosing pharmacokinetic factors (ultrarapid metabolism) for drug failure.

Therefore, the integration of information on a patient's genotype and phenotype (assessed using TDM) provides a rational basis for drug and dose selection and for dose regimen optimization of many clinically useful psychotropic drugs [31]. This approach is also valuable for the interpretation of psychotropic drug response in the context of older people with multiple comorbidities and complex polypharmacy [19]. Furthermore, inhibition or induction of drug metabolism at the CYP level is probably the main reason why the drug metabolic genotype does not reflect the phenotype, which can be accurately assessed in TDM [161].

\section{Antiepileptic drugs}

Drug treatment of epilepsy is characterized by the unpredictability of the efficacy of the drug, of ADRs and of optimal doses in individual patients which, at least in part, is a consequence of genetic variation. Since genetic variability in drug metabolism was reported to affect the treatment with phenytoin more than 25 years ago, the ultimate goal of pharmacogenetics is to use the genetic makeup of an individual to predict drug response and efficacy as well as potential adverse drug events (ADRs).

The influence of pharmacogenetics in the metabolism of antiepilepileptic drugs is not very striking; therefore, it is not surprising that there are no treatment guidelines taking pharmacogenetic data into account. In contrast, the traditional and validated TDM approach, representing a direct 'phenotype' assessment, still remains the method of choice when an individualized dosing regimen is anticipated [173, 174].

\section{Carbamazepine}

In Asian patients, the presence of a particular $H L A$ allele, $H L A-B^{*} 1502$, confers a higher risk for Stevens-Johnson syndrome (SJS) or toxical epidermal necrolysis (TEN) when carbamazepine is used [175]. Therefore, according to medication labeling, prior to initiating therapy with carbamazapine, testing for $H L A-B^{*} 1502$ should be performed in patients with ancestry in populations in which $H L A-B^{*} 1502$ may be present. In deciding which patients to screen, the rates provided above for the prevalence of $H L A-B^{*} 1502$ may offer a rough guide, keeping in mind the limitations of these figures due to wide variability in rates even within ethnic groups, the difficulty in ascertaining ethnic ancestry and the likelihood of mixed ancestry. Carbamazepine should not be used in patients positive for $H L A-B^{*} 1502$ unless the benefits clearly outweigh the risks. Tested patients who are found to be negative for the allele are thought to have a low risk of SJS/TEN.

For genetically at-risk patients, high-resolution HLA$B^{*} 1502$ typing is recommended (Table 1 ). The test is positive if either one or two $H L A-B^{*} 1502$ alleles are detected and negative if no $H L A-B^{*} 1502$ alleles are detected.

\section{Phenytoin}

Of all the antiepileptic drugs, only phenytoin undergoes significant metabolism by cytochrome P450 isozymes, mainly by CYP2C9 and to a lesser extent by CYP2C19. $C Y P 2 C 9$ variant alleles, such as $C Y P 2 C 9^{*} 3$ or $C Y P 2 C 9^{*} 6$, have been linked to severe toxicity [176, 177]; consequently, Kerb et al. [178] suggested that the analysis of CYP2C9 may have predictive value in the daily clinical practice. Hung et al. [179] established a number of guidelines for phenytoin dosage adjustment based on the impact of CYP2C9 and CYPC19 polymorphisms on pharmacokinetics data. In their study, doses ranged from $5.5-7 \mathrm{mg} / \mathrm{kg} / \mathrm{day}$ in double EMs to just $2-3 \mathrm{mg} / \mathrm{kg} /$ day in PMs of both genes.

\section{Translating genotype data into a valid measure of drug response (phenotype)}

There is absolutely no doubt that genetic biomarkers can play an important role in identifying responders and nonresponders, avoiding toxicity and adjusting the dosage of drugs to optimize their efficacy and safety [180].

Historically, many of the classically defined pharmacogenetic traits were monogenic, whereby allelic variants at a single gene locus produced clearly discernible population phenotypes. It is now becoming increasingly apparent that the majority of drug-response phenotypes are likely to result from significant variation at multiple gene loci, and the technological challenges of dissecting out the contributions of numerous genetic variants at multiple genes (on a background of multiple environmental factors) and reducing this information to a predictive diagnostic test are 
formidable [13]. Therefore, despite significant progress in pharmacogenetic research, the translation of these findings into drug discovery, drug development or clinical practice has proved to be surprisingly disappointing.

There are many gaps that limit the application of pharmacogenetic information. First, the human genome is unexpectedly complex, leading to many difficulties in accurately and unequivocally describing genotypes and phenotypes [167]. It is rather complex to focus on candidate-genes for which there is some biological or chemical reason to hypothesize their possible involvement in the response to a particular drug, and many pharmacogenetic tests that evaluate only a few candidate genes miss important contributions of variation in other genes, thereby reducing the predictive value of the test and limiting its application in different populations [10, 181]. Pharmacogenetic tests could be more clinically applicable if they included a comprehensive survey of variation in the human genome and appreciation of the multigenic nature of many phenotypes of drug disposition and response.

Secondly, the achievement of a tight link between genotype and the effect of a specific drug treatment accounts only for $10-15 \%$ of all cases [182]. Most drugresponse phenotypes are shaped by a combination of environmental, genetic and gene-environment interactions, but we do have fragmentary information on how the interplay between genetics and environment affects the drug response. Therefore, an essential step on the road toward delivery of pharmacogenetic information is to develop and utilize efficient methods for identifying the genetic and environmental variants affecting drug metabolism and drug action [25, 29, 183]. For example,, older people (especially those who are frail) are underrepresented in pivotal clinical trials that are used to provide information for optimal dose regimen decisions [19].

Epigenetics is among the many reasons for this inability to identify an unequivocal genotype-phenotype association. Failure to account for subject environment can have a deleterious effect on the interpretation of genetic studies. Although interindividual discrepancies in drug response are often attributed to genetic heterogeneity, many of these cannot be explained by DNA sequence variation. Fortunately, there seems to be increasing appreciation of the interaction of genes, drugs and the environment [184]. In this context, pharmacoepigenetics potentially offers another level of explanation for interindividual variations in drug response that cannot be accounted for on the basis of genetic polymorphism. The term 'epigenetics' refers to phenotypic changes that do not involve any alteration in DNA sequence offering the bridge that connects the environment and the genome [185].

Third, the use of pharmacogenetic tests as a standard of care for drug therapy has to overcome three significant hurdles: (1) benefits relative to the use of the available alternative biomarker (e.g., the INR for warfarin); (2) the need for specific dosing guidelines and interpretation resulting from testing; (3) the lack of drug efficacy is quite as costly as drug toxicity, especially with expensive drugs [186], and pharmacogenetic testing has to demonstrate improvements not only in short-term toxicity but also in long-term efficacy [13]. It is not sufficient that a pharmacogenetic test simply show a significant association with outcomes. A new test should provide predictive capability that augments our existing ability to predict drug response. In addition, these tests should be designed to predict the necessity of a change in dose or drug.

Finally, despite scientific findings, there are other barriers that block the development and implementation of pharmacogenetic tests. These include economic, commercial, political, and educational barriers to the effective communication of clinically useful information to practitioners and patients [186, 187].

In order to obtain clinically and commercially robust pharmacogenetic testing that can be applied, support from regulatory agencies through the establishment of guidelines is needed to potentiate specific drugs for which predictive genotyping should be taken into consideration before drug therapy is initiated.

Formal prospective controlled clinical trials would be, however, an important step in reconciling pharmacogenetics and TDM as a way to understand the determinants of drug response for many clinically useful drugs.

Acknowledgments The research programmes of the authors have been partly supported by the Plan Nacional de Investigación Científica, Desarrollo e Innovación Tecnológica $(\mathrm{I}+\mathrm{D}+\mathrm{I})$, Instituto de Salud Carlos III, Subdirección General de Evaluación y Fomento de la Investigación, PI071152; Ayudas para la consolidación y apoyo a grupos de investigación de Extremadura, GRU09015 (Orden de 17 de diciembre de 2008, DOE 5 de enero de 2009), and grant PRI08A008 from Consejería de Economía, Comercio e Innovación, Junta de Extremadura, Mérida (Spain).

\section{References}

1. Spear BB, Heath-Chiozzi M, Huff J (2001) Clinical application of pharmacogenetics. Trends Mol Med 7:201-204

2. Lazarou J, Pomeranz BH, Corey PN (1998) Incidence of adverse drug reactions in hospitalized patients: a meta-analysis of prospective studies. JAMA 279:1200-1205

3. Nelson DR (2009) The cytochrome p450 homepage. Hum Genomics 4:59-65

4. Evans WE, Relling MV (1999) Pharmacogenomics: translating functional genomics into rational therapeutics. Science 286:487491

5. Phillips KA, Veenstra DL, Oren E, Lee JK, Sadee W (2001) Potential role of pharmacogenomics in reducing adverse drug reactions: a systematic review. JAMA 286:2270-2279

6. Johansson I, Lundqvist E, Bertilsson L, Dahl ML, Sjoqvist F, Ingelman-Sundberg M (1993) Inherited amplification of an 
active gene in the cytochrome P450 CYP2D locus as a cause of ultrarapid metabolism of debrisoquine. Proc Natl Acad Sci USA 90:11825-11829

7. Bertilsson L, Dahl ML, Dalen P, Al-Shurbaji A (2002) Molecular genetics of CYP2D6: clinical relevance with focus on psychotropic drugs. Br J Clin Pharmacol 53:111-122

8. Chou WH, Yan FX, de Leon J, Barnhill J, Rogers T, Cronin M, Pho M, Xiao V, Ryder TB, Liu WW, Teiling C, Wedlund PJ (2000) Extension of a pilot study: impact from the cytochrome P450 2D6 polymorphism on outcome and costs associated with severe mental illness. J Clin Psychopharmacol 20:246-251

9. Sjoqvist F, Eliasson E (2007) The convergence of conventional therapeutic drug monitoring and pharmacogenetic testing in personalized medicine: focus on antidepressants. Clin Pharmacol Ther 81:899-902

10. Hansen NT, Brunak S, Altman RB (2009) Generating genomescale candidate gene lists for pharmacogenomics. Clin Pharmacol Ther 86:183-189

11. Frueh FW, Amur S, Mummaneni P, Epstein RS, Aubert RE, DeLuca TM, Verbrugge RR, Burckart GJ, Lesko LJ (2008) Pharmacogenomic biomarker information in drug labels approved by the United States food and drug administration: prevalence of related drug use. Pharmacotherapy 28:992-998

12. de Leon J, Armstrong SC, Cozza KL (2006) Clinical guidelines for psychiatrists for the use of pharmacogenetic testing for CYP450 2D6 and CYP450 2C19. Psychosomatics 47:75-85

13. Flockhart DA, Skaar T, Berlin DS, Klein TE, Nguyen AT (2009) Clinically available pharmacogenomics tests. Clin Pharmacol Ther 86:109-113

14. Nowack R, Andrassy J, Fischereder M, Unger M (2009) Effects of dietary factors on drug transport and metabolism: the impact on dosage guidelines in transplant patients. Clin Pharmacol Ther 85:439-443

15. Caccia S, Garattini S, Pasina L, Nobili A (2009) Predicting the clinical relevance of drug interactions from pre-approval studies. Drug Saf 32:1017-1039

16. Nemeroff CB, Preskorn SH, Devane CL (2007) Antidepressant drug-drug interactions: clinical relevance and risk management. CNS Spectr 12:1-13

17. Urichuk L, Prior TI, Dursun S, Baker G (2008) Metabolism of atypical antipsychotics: involvement of cytochrome p450 enzymes and relevance for drug-drug interactions. Curr Drug Metab 9:410-418

18. Ekselius L, Bengtsson F, von Knorring L (2000) Non-compliance with pharmacotherapy of depression is associated with a sensation seeking personality. Int Clin Psychopharmacol 15:273-278

19. McLachlan AJ, Hilmer SN, Le Couteur DG (2009) Variability in response to medicines in older people: phenotypic and genotypic factors. Clin Pharmacol Ther 85:431-433

20. Morgan ET (2009) Impact of infectious and inflammatory disease on cytochrome P450-mediated drug metabolism and pharmacokinetics. Clin Pharmacol Ther 85:434-438

21. Morgan ET, Goralski KB, Piquette-Miller M, Renton KW, Robertson GR, Chaluvadi MR, Charles KA, Clarke SJ, Kacevska M, Liddle C, Richardson TA, Sharma R, Sinal CJ (2008) Regulation of drug-metabolizing enzymes and transporters in infection, inflammation, and cancer. Drug Metab Dispos 36:205-216

22. Schmith VD, Foss JF (2008) Effects of inflammation on pharmacokinetics/pharmacodynamics: increasing recognition of its contribution to variability in response. Clin Pharmacol Ther 83:809-811

23. Sproule BA, Naranjo CA, Brenmer KE, Hassan PC (1997) Selective serotonin reuptake inhibitors and CNS drug interactions. A critical review of the evidence. Clin Pharmacokinet $33: 454-471$
24. Thomas M, Boggs AA, DiPaula B, Siddiqi S (2010) Adverse drug reactions in hospitalized psychiatric patients. Ann Pharmacother 44:819-825

25. Carrillo JA, Benitez J (2000) Clinically significant pharmacokinetic interactions between dietary caffeine and medications. Clin Pharmacokinet 39:127-153

26. Davies SJ, Eayrs S, Pratt P, Lennard MS (2004) Potential for drug interactions involving cytochromes P450 2D6 and 3A4 on general adult psychiatric and functional elderly psychiatric wards. Br J Clin Pharmacol 57:464-472

27. Spina E, de Leon J (2007) Metabolic drug interactions with newer antipsychotics: a comparative review. Basic Clin Pharmacol Toxicol 100:4-22

28. Carrillo JA, Herraiz AG, Ramos SI, Benitez J (1998) Effects of caffeine withdrawal from the diet on the metabolism of clozapine in schizophrenic patients. J Clin Psychopharmacol 18:311-316

29. Carrillo JA, Ramos SI, Herraiz AG, Llerena A, Agundez JA, Berecz R, Duran M, Benitez J (1999) Pharmacokinetic interaction of fluvoxamine and thioridazine in schizophrenic patients. $\mathrm{J}$ Clin Psychopharmacol 19:494-499

30. Christensen M, Tybring G, Mihara K, Yasui-Furokori N, Carrillo JA, Ramos SI, Andersson K, Dahl ML, Bertilsson L (2002) Low daily $10-\mathrm{mg}$ and $20-\mathrm{mg}$ doses of fluvoxamine inhibit the metabolism of both caffeine (cytochrome P4501A2) and omeprazole (cytochrome P4502C19). Clin Pharmacol Ther 71:141-152

31. Sjoqvist F, Bertilsson L (1984) Clinical pharmacology of antidepressant drugs: pharmacogenetics. Adv Biochem Psychopharmacol 39:359-372

32. Hiemke C (2008) Clinical utility of drug measurement and pharmacokinetics: therapeutic drug monitoring in psychiatry. Eur J Clin Pharmacol 64:159-166

33. Alexanderson B, Evans DA, Sjoqvist F (1969) Steady-state plasma levels of nortriptyline in twins: influence of genetic factors and drug therapy. Br Med J 4:764-768

34. Asberg M, Cronholm B, Sjoqvist F, Tuck D (1971) Relationship between plasma level and therapeutic effect of nortriptyline. $\mathrm{Br}$ Med J 3:331-334

35. Baumann P (1986) Pharmacogenetics of antidepressant metabolism. Value of the debrisoquin test. Encephale 12:143-148

36. Baumann P, Hiemke C, Ulrich S, Eckermann G, Gaertner I, Gerlach M, Kuss HJ, Laux G, Muller-Oerlinghausen B, Rao ML, Riederer P, Zernig G, Arbeitsge-meinschaft fur neuropsychopharmakologie und pharmakopsychiatrie (2004) The AGNPTDM expert group consensus guidelines: therapeutic drug monitoring in psychiatry. Pharmacopsychiatry 37:243-265

37. Marquet P, Rousseau A (2008) Pharmacokinetics and therapeutic drug monitoring of anticancer agents. Bull Cancer 95:903-909

38. Rotger M, Telenti A (2008) Optimizing efavirenz treatment: CYP2B6 genotyping or therapeutic drug monitoring? Eur J Clin Pharmacol 64:335-336

39. Wallemacq PE (2004) Therapeutic monitoring of immunosuppressant drugs. Where are we? Clin Chem Lab Med 42:1204 1211

40. Kahan BD, Keown P, Levy GA, Johnston A (2002) Therapeutic drug monitoring of immunosuppressant drugs in clinical practice. Clin Ther 24:330-350, discussion 329

41. Ensom MH, Chang TK, Patel P (2001) Pharmacogenetics: the therapeutic drug monitoring of the future? Clin Pharmacokinet 40:783-802

42. Askanase AD, Wallace DJ, Weisman MH, Tseng CE, Bernstein L, Belmont HM, Seidman E, Ishimori M, Izmirly PM, Buyon JP (2009) Use of pharmacogenetics, enzymatic phenotyping, and metabolite monitoring to guide treatment with azathioprine in patients with systemic lupus erythematosus. J Rheumatol 36:89-95

43. Jaquenoud Sirot E, van der Velden JW, Rentsch K, Eap CB, Baumann P (2006) Therapeutic drug monitoring and pharmaco- 
genetic tests as tools in pharmacovigilance. Drug Saf 29:735768

44. Sattler M, Guengerich FP, Yun CH, Christians U, Sewing KF (1992) Cytochrome P-450 3A enzymes are responsible for biotransformation of FK506 and rapamycin in man and rat. Drug Metab Dispos 20:753-761

45. Thervet E, Anglicheau D, King B, Schlageter MH, Cassinat B, Beaune P, Legendre C, Daly AK (2003) Impact of cytochrome p450 3A5 genetic polymorphism on tacrolimus doses and concentration-to-dose ratio in renal transplant recipients. Transplantation 76:1233-1235

46. Hesselink DA, van Schaik RH, van der Heiden IP, van der Werf M, Gregoor PJ, Lindemans J, Weimar W, van Gelder T (2003) Genetic polymorphisms of the CYP3A4, CYP3A5, and MDR-1 genes and pharmacokinetics of the calcineurin inhibitors cyclosporine and tacrolimus. Clin Pharmacol Ther 74:245-254

47. Haufroid V, Mourad M, Van Kerckhove V, Wawrzyniak J, De Meyer M, Eddour DC, Malaise J, Lison D, Squifflet JP, Wallemacq P (2004) The effect of CYP3A5 and MDR1 (ABCB1) polymorphisms on cyclosporine and tacrolimus dose requirements and trough blood levels in stable renal transplant patients. Pharmacogenetics 14:147-154

48. Goto M, Masuda S, Kiuchi T, Ogura Y, Oike F, Okuda M, Tanaka $\mathrm{K}$, Inui $\mathrm{K}$ (2004) CYP3A5*1-carrying graft liver reduces the concentration/oral dose ratio of tacrolimus in recipients of livingdonor liver transplantation. Pharmacogenetics 14:471-478

49. MacPhee IA, Fredericks S, Holt DW (2005) Does pharmacogenetics have the potential to allow the individualisation of immunosuppressive drug dosing in organ transplantation? Expert Opin Pharmacother 6:2593-2605

50. Tsuchiya K, Gatanaga H, Tachikawa N, Teruya K, Kikuchi Y, Yoshino M, Kuwahara T, Shirasaka T, Kimura S, Oka S (2004) Homozygous CYP2B6 *6 (Q172H and K262R) correlates with high plasma efavirenz concentrations in HIV-1 patients treated with standard efavirenz-containing regimens. Biochem Biophys Res Commun 319:1322-1326

51. Utecht KN, Hiles JJ, Kolesar J (2006) Effects of genetic polymorphisms on the pharmacokinetics of calcineurin inhibitors. Am J Health Syst Pharm 63:2340-2348

52. Akbas SH, Bilgen T, Keser I, Tuncer M, Yucetin L, Tosun O, Gultekin M, Luleci G (2006) The effect of MDR1 (ABCB1) polymorphism on the pharmacokinetic of tacrolimus in Turkish renal transplant recipients. Transplant Proc 38:1290-1292

53. Mourad M, Mourad G, Wallemacq P, Garrigue V, Van Bellingen C, Van Kerckhove V, De Meyer M, Malaise J, Eddour DC, Lison D, Squifflet JP, Haufroid V (2005) Sirolimus and tacrolimus trough concentrations and dose requirements after kidney transplantation in relation to CYP3A5 and MDR1 polymorphisms and steroids. Transplantation 80:977-984

54. Tada H, Tsuchiya N, Satoh S, Kagaya H, Li Z, Sato K, Miura M, Suzuki T, Kato T, Habuchi T (2005) Impact of CYP3A5 and MDR1(ABCB1) C3435T polymorphisms on the pharmacokinetics of tacrolimus in renal transplant recipients. Transplant Proc 37:1730-1732

55. Elens L, Capron A, Kerckhove VV, Lerut J, Mourad M, Lison D, Wallemacq P, Haufroid V (2007) $1199 \mathrm{G}>\mathrm{A}$ and $2677 \mathrm{G}>\mathrm{T} / \mathrm{A}$ polymorphisms of $\mathrm{ABCB} 1$ independently affect tacrolimus concentration in hepatic tissue after liver transplantation. Pharmacogenet Genomics 17:873-883

56. Kuypers DR, de Jonge H, Naesens M, Lerut E, Verbeke K, Vanrenterghem Y (2007) CYP3A5 and CYP3A4 but not MDR1 single-nucleotide polymorphisms determine long-term tacrolimus disposition and drug-related nephrotoxicity in renal recipients. Clin Pharmacol Ther 82:711-725

57. Hauser IA, Schaeffeler E, Gauer S, Scheuermann EH, Wegner B, Gossmann J, Ackermann H, Seidl C, Hocher B, Zanger UM,
Geiger H, Eichelbaum M, Schwab M (2005) ABCB1 genotype of the donor but not of the recipient is a major risk factor for cyclosporine-related nephrotoxicity after renal transplantation. J Am Soc Nephrol 16:1501-1511

58. Thervet E, Loriot MA, Barbier S, Buchler M, Ficheux M, Choukroun G, Toupance O, Touchard G, Alberti C, Le Pogamp P, Moulin B, Le Meur Y, Heng AE, Subra JF, Beaune P, Legendre C (2010) Optimization of initial tacrolimus dose using pharmacogenetic testing. Clin Pharmacol Ther 87:721-726

59. Koster RA, Dijkers EC, Uges DR (2009) Robust, highthroughput LC-MS/MS method for therapeutic drug monitoring of cyclosporine, tacrolimus, everolimus, and sirolimus in whole blood. Ther Drug Monit 31:116-125

60. Yates CR, Krynetski EY, Loennechen T, Fessing MY, Tai HL, Pui CH, Relling MV, Evans WE (1997) Molecular diagnosis of thiopurine S-methyltransferase deficiency: genetic basis for azathioprine and mercaptopurine intolerance. Ann Intern Med 126:608-614

61. Lennard L (2002) TPMT in the treatment of Crohn's disease with azathioprine. Gut 51:143-146

62. Ansari A, Hassan C, Duley J, Marinaki A, Shobowale-Bakre EM, Seed P, Meenan J, Yim A, Sanderson J (2002) Thiopurine methyltransferase activity and the use of azathioprine in inflammatory bowel disease. Aliment Pharmacol Ther 16:1743-1750

63. Dubinsky MC, Lamothe S, Yang HY, Targan SR, Sinnett D, Theoret Y, Seidman EG (2000) Pharmacogenomics and metabolite measurement for 6-mercaptopurine therapy in inflammatory bowel disease. Gastroenterology 118:705-713

64. Dubinsky MC, Yang H, Hassard PV, Seidman EG, Kam LY, Abreu MT, Targan SR, Vasiliauskas EA (2002) 6-MP metabolite profiles provide a biochemical explanation for 6-MP resistance in patients with inflammatory bowel disease. Gastroenterology 122:904-915

65. McLeod HL, Krynetski EY, Relling MV, Evans WE (2000) Genetic polymorphism of thiopurine methyltransferase and its clinical relevance for childhood acute lymphoblastic leukemia. Leukemia 14:567-572

66. Schaeffeler E, Fischer C, Brockmeier D, Wernet D, Moerike K, Eichelbaum M, Zanger UM, Schwab M (2004) Comprehensive analysis of thiopurine S-methyltransferase phenotype-genotype correlation in a large population of German-Caucasians and identification of novel TPMT variants. Pharmacogenetics $14: 407-417$

67. Otterness D, Szumlanski C, Lennard L, Klemetsdal B, Aarbakke J, Park-Hah JO, Iven H, Schmiegelow K, Branum E, O'Brien J, Weinshilboum R (1997) Human thiopurine methyltransferase pharmacogenetics: gene sequence polymorphisms. Clin Pharmacol Ther 62:60-73

68. McGovern DP, Travis SP, Duley J, Shobowale-Bakre el M, Dalton HR (2002) Azathioprine intolerance in patients with IBD may be imidazole-related and is independent of TPMT activity. Gastroenterology 122:838-839

69. Winter JW, Gaffney D, Shapiro D, Spooner RJ, Marinaki AM, Sanderson JD, Mills PR (2007) Assessment of thiopurine methyltransferase enzyme activity is superior to genotype in predicting myelosuppression following azathioprine therapy in patients with inflammatory bowel disease. Aliment Pharmacol Ther 25:1069-1077

70. Colombel JF, Ferrari N, Debuysere H, Marteau P, Gendre JP, Bonaz B, Soule JC, Modigliani R, Touze Y, Catala P, Libersa C, Broly F (2000) Genotypic analysis of thiopurine S-methyltransferase in patients with Crohn's disease and severe myelosuppression during azathioprine therapy. Gastroenterology 118:1025-1030

71. Marra CA, Esdaile JM, Anis AH (2002) Practical pharmacogenetics: the cost effectiveness of screening for thiopurine 
s-methyltransferase polymorphisms in patients with rheumatological conditions treated with azathioprine. J Rheumatol 29:2507-2512

72. Regueiro M, Mardini H (2002) Determination of thiopurine methyltransferase genotype or phenotype optimizes initial dosing of azathioprine for the treatment of Crohn's disease. J Clin Gastroenterol 35:240-244

73. Oh KT, Anis AH, Bae SC (2004) Pharmacoeconomic analysis of thiopurine methyltransferase polymorphism screening by polymerase chain reaction for treatment with azathioprine in Korea. Rheumatology (Oxford) 43:156-163

74. van den Akker-van Marle ME, Gurwitz D, Detmar SB, Enzing CM, Hopkins MM, Gutierrez de Mesa E, Ibarreta D (2006) Costeffectiveness of pharmacogenomics in clinical practice: a case study of thiopurine methyltransferase genotyping in acute lymphoblastic leukemia in Europe. Pharmacogenomics 7:783-792

75. Mendelsohn J, Baselga J (2006) Epidermal growth factor receptor targeting in cancer. Semin Oncol 33:369-385

76. Chung KY, Shia J, Kemeny NE, Shah M, Schwartz GK, Tse A, Hamilton A, Pan D, Schrag D, Schwartz L, Klimstra DS, Fridman D, Kelsen DP, Saltz LB (2005) Cetuximab shows activity in colorectal cancer patients with tumors that do not express the epidermal growth factor receptor by immunohistochemistry. J Clin Oncol 23:1803-1810

77. Saltz L (2005) Epidermal growth factor receptor-negative colorectal cancer: is there truly such an entity? Clin Colorectal Cancer 5[Suppl 2]:S98-S100

78. Dolgin E (2009) FDA narrows drug label usage. Nature 460:1069

79. Ceze N, Ternant D, Piller F, Degenne D, Azzopardi N, Dorval E, Watier H, Lecomte T, Paintaud G (2009) An enzyme-linked immunosorbent assay for therapeutic drug monitoring of cetuximab. Ther Drug Monit 31:597-601

80. Jabbour E, Cortes J, Kantarjian H (2007) Dasatinib for the treatment of Philadelphia chromosome-positive leukaemias. Expert Opin Investig Drugs 16:679-687

81. Haouala A, Zanolari B, Rochat B, Montemurro M, Zaman K, Duchosal MA, Ris HB, Leyvraz S, Widmer N, Decosterd LA (2009) Therapeutic drug monitoring of the new targeted anticancer agents imatinib, nilotinib, dasatinib, sunitinib, sorafenib and lapatinib by LC tandem mass spectrometry. J Chromatogr B Analyt Technol Biomed Life Sci 877:1982-1996

82. Gupta E, Lestingi TM, Mick R, Ramirez J, Vokes EE, Ratain MJ (1994) Metabolic fate of irinotecan in humans: correlation of glucuronidation with diarrhea. Cancer Res 54:3723-3725

83. Bosma PJ, Chowdhury JR, Bakker C, Gantla S, de Boer A, Oostra BA, Lindhout D, Tytgat GN, Jansen PL, Oude Elferink RP (1995) The genetic basis of the reduced expression of bilirubin UDP-glucuronosyltransferase 1 in Gilbert's syndrome. N Engl J Med 333:1171-1175

84. Monaghan G, Ryan M, Seddon R, Hume R, Burchell B (1996) Genetic variation in bilirubin UPD-glucuronosyltransferase gene promoter and Gilbert's syndrome. Lancet 347:578-581

85. Iyer L, Hall D, Das S, Mortell MA, Ramirez J, Kim S, Di Rienzo A, Ratain MJ (1999) Phenotype-genotype correlation of in vitro SN-38 (active metabolite of irinotecan) and bilirubin glucuronidation in human liver tissue with UGT1A1 promoter polymorphism. Clin Pharmacol Ther 65:576-582

86. Innocenti F, Undevia SD, Iyer L, Chen PX, Das S, Kocherginsky M, Karrison T, Janisch L, Ramirez J, Rudin CM, Vokes EE, Ratain MJ (2004) Genetic variants in the UDP-glucuronosyltransferase $1 \mathrm{~A} 1$ gene predict the risk of severe neutropenia of irinotecan. J Clin Oncol 22:1382-1388

87. Fakih MG, Ross ME, Starostik P (2007) Increased frequency of uridine diphosphate glucuronosyltransferase 1A1 7/7 in patients experiencing severe irinotecan-induced toxicities. Clin Colorectal Cancer 6:583-587
88. Sai K, Saeki M, Saito Y, Ozawa S, Katori N, Jinno H, Hasegawa R, Kaniwa N, Sawada J, Komamura K, Ueno K, Kamakura S, Kitakaze M, Kitamura Y, Kamatani N, Minami H, Ohtsu A, Shirao K, Yoshida T, Saijo N (2004) UGT1A1 haplotypes associated with reduced glucuronidation and increased serum bilirubin in irinotecan-administered Japanese patients with cancer. Clin Pharmacol Ther 75:501-515

89. Araki K, Fujita K, Ando Y, Nagashima F, Yamamoto W, Endo H, Miya T, Kodama K, Narabayashi M, Sasaki Y (2006) Pharmacogenetic impact of polymorphisms in the coding region of the UGT1A1 gene on SN-38 glucuronidation in Japanese patients with cancer. Cancer Sci 97:1255-1259

90. Ando Y, Fujita K, Sasaki Y, Hasegawa Y (2007) UGT1AI*6 and UGT1A1*27 for individualized irinotecan chemotherapy. Curr Opin Mol Ther 9:258-262

91. Jada SR, Lim R, Wong CI, Shu X, Lee SC, Zhou Q, Goh BC, Chowbay B (2007) Role of UGT1A1*6, UGT1A1*28 and ABCG2 c.421C $>$ A polymorphisms in irinotecan-induced neutropenia in Asian cancer patients. Cancer Sci 98:1461-1467

92. Ratain MJ (2006) From bedside to bench to bedside to clinical practice: an odyssey with irinotecan. Clin Cancer Res 12:1658-1660

93. Wu X, Hawse JR, Subramaniam M, Goetz MP, Ingle JN, Spelsberg TC (2009) The tamoxifen metabolite, endoxifen, is a potent antiestrogen that targets estrogen receptor alpha for degradation in breast cancer cells. Cancer Res 69:1722-1727

94. Desta Z, Ward BA, Soukhova NV, Flockhart DA (2004) Comprehensive evaluation of tamoxifen sequential biotransformation by the human cytochrome P450 system in vitro: prominent roles for CYP3A and CYP2D6. J Pharmacol Exp Ther 310:1062-1075

95. Jin Y, Desta Z, Stearns V, Ward B, Ho H, Lee KH, Skaar T, Storniolo AM, Li L, Araba A, Blanchard R, Nguyen A, Ullmer L, Hayden J, Lemler S, Weinshilboum RM, Rae JM, Hayes DF, Flockhart DA (2005) CYP2D6 genotype, antidepressant use, and tamoxifen metabolism during adjuvant breast cancer treatment. J Natl Cancer Inst 97:30-39

96. Borges S, Desta Z, Li L, Skaar TC, Ward BA, Nguyen A, Jin Y, Storniolo AM, Nikoloff DM, Wu L, Hillman G, Hayes DF, Stearns V, Flockhart DA (2006) Quantitative effect of CYP2D6 genotype and inhibitors on tamoxifen metabolism: implication for optimization of breast cancer treatment. Clin Pharmacol Ther 80:61-74

97. Goetz MP, Rae JM, Suman VJ, Safgren SL, Ames MM, Visscher DW, Reynolds C, Couch FJ, Lingle WL, Flockhart DA, Desta Z, Perez EA, Ingle JN (2005) Pharmacogenetics of tamoxifen biotransformation is associated with clinical outcomes of efficacy and hot flashes. J Clin Oncol 23:9312-9318

98. Wegman P, Elingarami S, Carstensen J, Stal O, Nordenskjold B, Wingren S (2007) Genetic variants of CYP3A5, CYP2D6, SULT1A1, UGT2B15 and tamoxifen response in postmenopausal patients with breast cancer. Breast Cancer Res 9:R7

99. Goetz MP, Knox SK, Suman VJ, Rae JM, Safgren SL, Ames MM, Visscher DW, Reynolds C, Couch FJ, Lingle WL, Weinshilboum RM, Fritcher EG, Nibbe AM, Desta Z, Nguyen A, Flockhart DA, Perez EA, Ingle JN (2007) The impact of cytochrome P450 2D6 metabolism in women receiving adjuvant tamoxifen. Breast Cancer Res Treat 101:113-121

100. Goetz MP, Kamal A, Ames MM (2008) Tamoxifen pharmacogenomics: the role of CYP2D6 as a predictor of drug response. Clin Pharmacol Ther 83:160-166

101. Schroth W, Goetz MP, Hamann U, Fasching PA, Schmidt M, Winter S, Fritz P, Simon W, Suman VJ, Ames MM, Safgren SL, Kuffel MJ, Ulmer HU, Bolander J, Strick R, Beckmann MW, Koelbl H, Weinshilboum RM, Ingle JN, Eichelbaum M, Schwab M, Brauch H (2009) Association between CYP2D6 polymorphisms and outcomes among women with early stage breast cancer treated with tamoxifen. JAMA 302:1429-1436 
102. Heller T, Kirchheiner J, Armstrong VW, Luthe H, Tzvetkov M, Brockmoller J, Oellerich M (2006) AmpliChip CYP450 GeneChip: a new gene chip that allows rapid and accurate CYP2D6 genotyping. Ther Drug Monit 28:673-677

103. Esteve-Romero J, Ochoa-Aranda E, Bose D, Rambla-Alegre M, Peris-Vicente J, Martinavarro-Dominguez A (2010) Tamoxifen monitoring studies in breast cancer patients by micellar liquid chromatography. Anal Bioanal Chem 397:1557-1561

104. Piccart-Gebhart MJ, Procter M, Leyland-Jones B, Goldhirsch A, Untch M, Smith I, Gianni L, Baselga J, Bell R, Jackisch C, Cameron D, Dowsett M, Barrios CH, Steger G, Huang CS, Andersson M, Inbar M, Lichinitser M, Lang I, Nitz U, Iwata H, Thomssen C, Lohrisch C, Suter TM, Ruschoff J, Suto T, Greatorex V, Ward C, Straehle C, McFadden E, Dolci MS, Gelber RD (2005) Trastuzumab after adjuvant chemotherapy in HER2-positive breast cancer. N Engl J Med 353:1659-1672

105. Romond EH, Perez EA, Bryant J, Suman VJ, GC E Jr, Davidson NE, Tan-Chiu E, Martino S, Paik S, Kaufman PA, Swain SM, Pisansky TM, Fehrenbacher L, Kutteh LA, Vogel VG, Visscher DW, Yothers G, Jenkins RB, Brown AM, Dakhil SR, Mamounas EP, Lingle WL, Klein PM, Ingle JN, Wolmark N (2005) Trastuzumab plus adjuvant chemotherapy for operable HER2positive breast cancer. N Engl J Med 353:1673-1684

106. US Food and Drug Administration (2009) Table of valid genomic biomarkers in the context of approved drug labels. Available at: http://www.fda.gov/Drugs/ScienceResearch/ ResearchAreas/Pharmacogenetics/ucm083378.htm. Accessed $10 / 142009$

107. Sparano JA (2001) Cardiac toxicity of trastuzumab (Herceptin): implications for the design of adjuvant trials. Semin Oncol 28:20-27

108. Beauclair S, Formento P, Fischel JL, Lescaut W, Largillier R, Chamorey E, Hofman P, Ferrero JM, Pages G, Milano G (2007) Role of the HER2 [Ile655Val] genetic polymorphism in tumorogenesis and in the risk of trastuzumab-related cardiotoxicity. Ann Oncol 18:1335-1341

109. Pirmohamed M, James S, Meakin S, Green C, Scott AK, Walley TJ, Farrar K, Park BK, Breckenridge AM (2004) Adverse drug reactions as cause of admission to hospital: prospective analysis of 18820 patients. Br Med J 329:15-19

110. Yasar U, Eliasson E, Dahl ML, Johansson I, Ingelman-Sundberg M, Sjoqvist F (1999) Validation of methods for CYP2C9 genotyping: frequencies of mutant alleles in a Swedish population. Biochem Biophys Res Commun 254:628-631

111. Margaglione M, Colaizzo D, D'Andrea G, Brancaccio V, Ciampa A, Grandone E, Di Minno G (2000) Genetic modulation of oral anticoagulation with warfarin. Thromb Haemost 84:775-778

112. Higashi MK, Veenstra DL, Kondo LM, Wittkowsky AK, Srinouanprachanh SL, Farin FM, Rettie AE (2002) Association between CYP2C9 genetic variants and anticoagulation-related outcomes during warfarin therapy. JAMA 287:1690-1698

113. Visser LE, van Vliet M, van Schaik RH, Kasbergen AA, De Smet PA, Vulto AG, Hofman A, van Duijn CM, Stricker BH (2004) The risk of overanticoagulation in patients with cytochrome P450 CYP2C9*2 or CYP2C9*3 alleles on acenocoumarol or phenprocoumon. Pharmacogenetics 14:27-33

114. Voora D, Eby C, Linder MW, Milligan PE, Bukaveckas BL, McLeod HL, Maloney W, Clohisy J, Burnett RS, Grosso L, Gatchel SK, Gage BF (2005) Prospective dosing of warfarin based on cytochrome P-450 2C9 genotype. Thromb Haemost 93:700-705

115. Rieder MJ, Reiner AP, Gage BF, Nickerson DA, Eby CS, McLeod HL, Blough DK, Thummel KE, Veenstra DL, Rettie AE (2005) Effect of VKORC1 haplotypes on transcriptional regulation and warfarin dose. N Engl J Med 352:2285-2293

116. Osman A, Enstrom C, Arbring K, Soderkvist P, Lindahl TL (2006) Main haplotypes and mutational analysis of vitamin K epoxide reductase (VKORC1) in a Swedish population: a retrospective analysis of case records. J Thromb Haemost 4:1723-1729

117. Rosove MH, Grody WW (2009) Should we be applying warfarin pharmacogenetics to clinical practice? No, not now. Ann Intern Med 151(270-3):W95

118. Gage BF, Lesko LJ (2008) Pharmacogenetics of warfarin: regulatory, scientific, and clinical issues. J Thromb Thrombolysis 25:45-51

119. Rost S, Fregin A, Ivaskevicius V, Conzelmann E, Hortnagel K, Pelz HJ, Lappegard K, Seifried E, Scharrer I, Tuddenham EG, Muller CR, Strom TM, Oldenburg J (2004) Mutations in VKORC1 cause warfarin resistance and multiple coagulation factor deficiency type 2. Nature 427:537-541

120. Loebstein R, Dvoskin I, Halkin H, Vecsler M, Lubetsky A, Rechavi G, Amariglio N, Cohen Y, Ken-Dror G, Almog S, Gak E (2007) A coding VKORC1 Asp36Tyr polymorphism predisposes to warfarin resistance. Blood 109:2477-2480

121. Chu K, Wu SM, Stanley T, Stafford DW, High KA (1996) A mutation in the propeptide of Factor IX leads to warfarin sensitivity by a novel mechanism. J Clin Invest 98:1619-1625

122. Oldenburg J, Quenzel EM, Harbrecht U, Fregin A, Kress W, Muller CR, Hertfelder HJ, Schwaab R, Brackmann HH, Hanfland P (1997) Missense mutations at ALA-10 in the factor IX propeptide: an insignificant variant in normal life but a decisive cause of bleeding during oral anticoagulant therapy. $\mathrm{Br} \mathrm{J}$ Haematol 98:240-244

123. Shikata E, Ieiri I, Ishiguro $\mathrm{S}$, Aono $\mathrm{H}$, Inoue $\mathrm{K}$, Koide T, Ohgi $\mathrm{S}$, Otsubo K (2004) Association of pharmacokinetic (CYP2C9) and pharmacodynamic (factors II, VII, IX, and X; proteins S and C; and gamma-glutamyl carboxylase) gene variants with warfarin sensitivity. Blood 103:2630-2635

124. Wadelius M, Sorlin K, Wallerman O, Karlsson J, Yue QY, Magnusson PK, Wadelius C, Melhus H (2004) Warfarin sensitivity related to CYP2C9, CYP3A5, ABCB1 (MDR1) and other factors. Pharmacogenomics J 4:40-48

125. Marsh S, McLeod HL (2006) Pharmacogenomics: from bedside to clinical practice. Hum Mol Genet 15[Spec No 1]:R89-R93

126. Oates A, Jackson PR, Austin CA, Channer KS (1998) A new regimen for starting warfarin therapy in out-patients. Br J Clin Pharmacol 46:157-161

127. O'Connell MB, Kowal PR, Allivato CJ, Repka TL (2000) Evaluation of warfarin initiation regimens in elderly inpatients. Pharmacotherapy 20:923-930

128. Sconce EA, Khan TI, Wynne HA, Avery P, Monkhouse L, King BP, Wood P, Kesteven P, Daly AK, Kamali F (2005) The impact of CYP2C9 and VKORC1 genetic polymorphism and patient characteristics upon warfarin dose requirements: proposal for a new dosing regimen. Blood 106:2329-2333

129. Wadelius M, Chen LY, Downes K, Ghori J, Hunt S, Eriksson N, Wallerman O, Melhus H, Wadelius C, Bentley D, Deloukas P (2005) Common VKORC1 and GGCX polymorphisms associated with warfarin dose. Pharmacogenomics J 5:262-270

130. Wadelius M, Chen LY, Lindh JD, Eriksson N, Ghori MJ, Bumpstead S, Holm L, McGinnis R, Rane A, Deloukas P (2009) The largest prospective warfarin-treated cohort supports genetic forecasting. Blood 113:784-792

131. Millican EA, Lenzini PA, Milligan PE, Grosso L, Eby C, Deych E, Grice G, Clohisy JC, Barrack RL, Burnett RS, Voora D, Gatchel S, Tiemeier A, Gage BF (2007) Genetic-based dosing in orthopedic patients beginning warfarin therapy. Blood 110:15111515

132. Hylek EM, Evans-Molina C, Shea C, Henault LE, Regan S (2007) Major hemorrhage and tolerability of warfarin in the first year of therapy among elderly patients with atrial fibrillation. Circulation 115:2689-2696 
133. Miao L, Yang J, Huang C, Shen Z (2007) Contribution of age, body weight, and $\mathrm{CYP} 2 \mathrm{C} 9$ and VKORC1 genotype to the anticoagulant response to warfarin: proposal for a new dosing regimen in Chinese patients. Eur J Clin Pharmacol 63:11351141

134. International Warfarin Pharmacogenetics Consortium, Klein TE, Altman RB, Eriksson N, Gage BF, Kimmel SE, Lee MT, Limdi NA, Page D, Roden DM, Wagner MJ, Caldwell MD, Johnson JA (2009) Estimation of the warfarin dose with clinical and pharmacogenetic data. N Engl J Med 360:753-764

135. Takeuchi F, McGinnis R, Bourgeois S, Barnes C, Eriksson N, Soranzo N, Whittaker P, Ranganath V, Kumanduri V, McLaren W, Holm L, Lindh J, Rane A, Wadelius M, Deloukas P (2009) A genome-wide association study confirms VKORC1, CYP2C9, and CYP4F2 as principal genetic determinants of warfarin dose. PLoS Genet 5:e1000433

136. Phillips E, Mallal S (2007) Drug hypersensitivity in HIV. Curr Opin Allergy Clin Immunol 7:324-330

137. Hetherington S, McGuirk S, Powell G, Cutrell A, Naderer O, Spreen B, Lafon S, Pearce G, Steel H (2001) Hypersensitivity reactions during therapy with the nucleoside reverse transcriptase inhibitor abacavir. Clin Ther 23:1603-1614

138. Peyriere H, Guillemin V, Lotthe A, Baillat V, Fabre J, Favier C, Atoui N, Hansel S, Hillaire-Buys D, Reynes J (2003) Reasons for early abacavir discontinuation in HIV-infected patients. Ann Pharmacother 37:1392-1397

139. Mallal S, Nolan D, Witt C, Masel G, Martin AM, Moore C, Sayer D, Castley A, Mamotte C, Maxwell D, James I, Christiansen FT (2002) Association between presence of HLA-B*5701, HLADR7, and HLA-DQ3 and hypersensitivity to HIV-1 reversetranscriptase inhibitor abacavir. Lancet 359:727-732

140. Hetherington S, Hughes AR, Mosteller M, Shortino D, Baker KL, Spreen W, Lai E, Davies K, Handley A, Dow DJ, Fling ME, Stocum M, Bowman C, Thurmond LM, Roses AD (2002) Genetic variations in HLA-B region and hypersensitivity reactions to abacavir. Lancet 359:1121-1122

141. Hughes DA, Vilar FJ, Ward CC, Alfirevic A, Park BK, Pirmohamed M (2004) Cost-effectiveness analysis of HLA B*5701 genotyping in preventing abacavir hypersensitivity. Pharmacogenetics 14:335-342

142. Hughes AR, Mosteller M, Bansal AT, Davies K, Haneline SA, Lai EH, Nangle K, Scott T, Spreen WR, Warren LL, Roses AD (2004) Association of genetic variations in HLA-B region with hypersensitivity to abacavir in some, but not all, populations. Pharmacogenomics 5:203-211

143. Lucas A, Nolan D, Mallal S (2007) HLA-B*5701 screening for susceptibility to abacavir hypersensitivity. J Antimicrob Chemother 59:591-593

144. Martin AM, Nolan D, Gaudieri S, Almeida CA, Nolan R, James I, Carvalho F, Phillips E, Christiansen FT, Purcell AW, McCluskey J, Mallal S (2004) Predisposition to abacavir hypersensitivity conferred by HLA-B*5701 and a haplotypic Hsp70-Hom variant. Proc Natl Acad Sci USA 101:4180-4185

145. Rauch A, Nolan D, Martin A, McKinnon E, Almeida C, Mallal S (2006) Prospective genetic screening decreases the incidence of abacavir hypersensitivity reactions in the Western Australian HIV cohort study. Clin Infect Dis 43:99-102

146. Reeves I, Churchill D, Fisher M (2006) Screening for HLAB*5701 reduces the frequency of abacavir hypersensitivity reactions. Antivir Ther 11:S1-S192

147. Cutrell AG, Hernandez JE, Fleming JW, Edwards MT, Moore MA, Brothers CH, Scott TR (2004) Updated clinical risk factor analysis of suspected hypersensitivity reactions to abacavir. Ann Pharmacother 38:2171-2172

148. Hammond E, Almeida CA, Mamotte C, Nolan D, Phillips E, Schollaardt TA, Gill MJ, Angel JB, Neurath D, Li J, Giulivi T,
McIntyre C, Koultchitski G, Wong B, Reis M, Rachlis A, Cole DE, Chew CB, Neifer S, Lalonde R, Roger M, Jeanneau A, Mallal S (2007) External quality assessment of HLA-B*5701 reporting: an international multicentre survey. Antivir Ther 12:1027-1032

149. Donnerer J, Kronawetter M, Kapper A, Haas I, Kessler HH (2003) Therapeutic drug monitoring of the HIV/AIDS drugs abacavir, zidovudine, efavirenz, nevirapine, indinavir, lopinavir, and nelfinavir. Pharmacology 69:197-204

150. Donnerer J, Haas BJ, Kessler HH (2008) Single-measurement therapeutic drug monitoring of the HIV/AIDS drugs abacavir, zidovudine, lamivudine, efavirenz, nevirapine, lopinavir and nelfinavir. Pharmacology 82:287-292

151. van Lunzen J (2007) How will CCR5 antagonists influence the recommendations for the antiretroviral treatment of HIV-1 infection. Eur J Med Res 12:435-440

152. Mueller MC, Bogner JR (2007) Treatment with CCR5 antagonists: which patient may have a benefit? Eur J Med Res 12:441452

153. Lorenzen T, Stoehr A, Walther I, Plettenberg A (2007) CCR5 antagonists in the treatment of treatment-experienced patients infected with CCR5 tropic HIV-1. Eur J Med Res 12:419425

154. D'Avolio A, Simiele M, Baietto L, Siccardi M, Sciandra M, Patanella S, Bonora S, Di Perri G (2010) A validated highperformance liquid chromatography-ultraviolet method for quantification of the CCR5 inhibitor maraviroc in plasma of HIVinfected patients. Ther Drug Monit 32:86-92

155. Fayet A, Beguin A, Zanolari B, Cruchon S, Guignard N, Telenti A, Cavassini M, Gunthard HF, Buclin T, Biollaz J, Rochat B, Decosterd LA (2009) A LC-tandem MS assay for the simultaneous measurement of new antiretroviral agents: raltegravir, maraviroc, darunavir, and etravirine. J Chromatogr B Anal Technol Biomed Life Sci 877:1057-1069

156. Rotger M, Colombo S, Furrer H, Bleiber G, Buclin T, Lee BL, Keiser O, Biollaz J, Decosterd L, Telenti A (2005) Influence of CYP2B6 polymorphism on plasma and intracellular concentrations and toxicity of efavirenz and nevirapine in HIV-infected patients. Pharmacogenet Genomics 15:1-5

157. Haas DW, Smeaton LM, Shafer RW, Robbins GK, Morse GD, Labbe L, Wilkinson GR, Clifford DB, D'Aquila RT, De Gruttola V, Pollard RB, Merigan TC, Hirsch MS, GA L Jr, Donahue JP, Kim RB (2005) Pharmacogenetics of long-term responses to antiretroviral regimens containing Efavirenz and/or Nelfinavir: an adult aids clinical trials group study. J Infect Dis 192:19311942

158. Haas DW, Ribaudo HJ, Kim RB, Tierney C, Wilkinson GR, Gulick RM, Clifford DB, Hulgan T, Marzolini C, Acosta EP (2004) Pharmacogenetics of efavirenz and central nervous system side effects: an adult AIDS clinical trials group study. AIDS 18:2391-2400

159. Nyakutira C, Roshammar D, Chigutsa E, Chonzi P, Ashton M, Nhachi C, Masimirembwa C (2008) High prevalence of the CYP2B6 516G->T $(* 6)$ variant and effect on the population pharmacokinetics of efavirenz in HIV/AIDS outpatients in Zimbabwe. Eur J Clin Pharmacol 64:357-365

160. Martin J, Deslandes G, Dailly E, Renaud C, Reliquet V, Raffi F, Jolliet P (2009) A liquid chromatography-tandem mass spectrometry assay for quantification of nevirapine, indinavir, atazanavir, amprenavir, saquinavir, ritonavir, lopinavir, efavirenz, tipranavir, darunavir and maraviroc in the plasma of patients infected with HIV. J Chromatogr B Anal Technol Biomed Life Sci 877:3072-3082

161. Dahl ML, Sjoqvist F (2000) Pharmacogenetic methods as a complement to therapeutic monitoring of antidepressants and neuroleptics. Ther Drug Monit 22:114-117 
162. Kirchheiner J, Nickchen K, Bauer M, Wong ML, Licinio J, Roots I, Brockmoller J (2004) Pharmacogenetics of antidepressants and antipsychotics: the contribution of allelic variations to the phenotype of drug response. Mol Psychiatry 9:442-473

163. Lessard E, Yessine MA, Hamelin BA, O'Hara G, LeBlanc J, Turgeon J (1999) Influence of CYP2D6 activity on the disposition and cardiovascular toxicity of the antidepressant agent venlafaxine in humans. Pharmacogenetics 9:435-443

164. Shams ME, Arneth B, Hiemke C, Dragicevic A, Muller MJ, Kaiser R, Lackner K, Hartter S (2006) CYP2D6 polymorphism and clinical effect of the antidepressant venlafaxine. J Clin Pharm Ther 31:493-502

165. Noehr-Jensen L, Zwisler ST, Larsen F, Sindrup SH, Damkier P, Nielsen F, Brosen K (2009) Impact of CYP2C19 phenotypes on escitalopram metabolism and an evaluation of pupillometry as a serotonergic biomarker. Eur J Clin Pharmacol 65:887-894

166. Kawanishi C, Lundgren S, Agren H, Bertilsson L (2004) Increased incidence of CYP2D6 gene duplication in patients with persistent mood disorders: ultrarapid metabolism of antidepressants as a cause of nonresponse. A pilot study. Eur J Clin Pharmacol 59:803-807

167. Gaedigk A, Simon SD, Pearce RE, Bradford LD, Kennedy MJ, Leeder JS (2008) The CYP2D6 activity score: translating genotype information into a qualitative measure of phenotype. Clin Pharmacol Ther 83:234-242

168. Stefansson H, Rujescu D, Cichon S, Pietilainen OP, Ingason A, Steinberg S, Fossdal R, Sigurdsson E, Sigmundsson T, BuizerVoskamp JE, Hansen T, Jakobsen KD, Muglia P, Francks C, Matthews PM, Gylfason A, Halldorsson BV, Gudbjartsson D, Thorgeirsson TE, Sigurdsson A, Jonasdottir A, Jonasdottir A, Bjornsson A, Mattiasdottir S, Blondal T, Haraldsson M, Magnusdottir BB, Giegling I, Moller HJ, Hartmann A, Shianna KV, Ge D, Need AC, Crombie C, Fraser G, Walker N, Lonnqvist J, Suvisaari J, Tuulio-Henriksson A, Paunio T, Toulopoulou T, Bramon E, Di Forti M, Murray R, Ruggeri M, Vassos E, Tosato S, Walshe M, Li T, Vasilescu C, Muhleisen TW, Wang AG, Ullum H, Djurovic S, Melle I, Olesen J, Kiemeney LA, Franke B, GROUP, Sabatti C, Freimer NB, Gulcher JR, Thorsteinsdottir U, Kong A, Andreassen OA, Ophoff RA, Georgi A, Rietschel M, Werge T, Petursson H, Goldstein DB, Nothen MM, Peltonen L, Collier DA, St Clair D, Stefansson K (2008) Large recurrent microdeletions associated with schizophrenia. Nature 455:232-236

169. Need AC, Ge D, Weale ME, Maia J, Feng S, Heinzen EL, Shianna KV, Yoon W, Kasperaviciute D, Gennarelli M, Strittmatter WJ, Bonvicini C, Rossi G, Jayathilake K, Cola PA, McEvoy JP, Keefe RS, Fisher EM, St Jean PL, Giegling I, Hartmann AM, Moller HJ, Ruppert A, Fraser G, Crombie C, Middleton LT, St Clair D, Roses AD, Muglia P, Francks C, Rujescu D, Meltzer HY, Goldstein DB (2009) A genome-wide investigation of SNPs and CNVs in schizophrenia. PLoS Genet 5:e1000373

170. Grossman I, Sullivan PF, Walley N, Liu Y, Dawson JR, Gumbs C, Gaedigk A, Leeder JS, McEvoy JP, Weale ME, Goldstein DB (2008) Genetic determinants of variable metabolism have little impact on the clinical use of leading antipsychotics in the CATIE study. Genet Med 10:720-729

171. Hammer W, Sjoqvist F (1967) Plasma levels of monomethylated tricyclic antidepressants during treatment with imipramine-like compounds. Life Sci 6:1895-1903

172. Mandrioli R, Forti GC, Raggi MA (2006) Fluoxetine metabolism and pharmacological interactions: the role of cytochrome $\mathrm{p} 450$. Curr Drug Metab 7:127-133

173. Klotz U (2007) The role of pharmacogenetics in the metabolism of antiepileptic drugs: pharmacokinetic and therapeutic implications. Clin Pharmacokinet 46:271-279

174. Anderson GD (2008) Pharmacokinetic, pharmacodynamic, and pharmacogenetic targeted therapy of antiepileptic drugs. Ther Drug Monit 30:173-180

175. Loscher W, Klotz U, Zimprich F, Schmidt D (2009) The clinical impact of pharmacogenetics on the treatment of epilepsy. Epilepsia 50:1-23

176. Kidd RS, Curry TB, Gallagher S, Edeki T, Blaisdell J, Goldstein JA (2001) Identification of a null allele of CYP2C9 in an African-American exhibiting toxicity to phenytoin. Pharmacogenetics 11:803-808

177. Brandolese R, Scordo MG, Spina E, Gusella M, Padrini R (2001) Severe phenytoin intoxication in a subject homozygous for CYP2C9*3. Clin Pharmacol Ther 70:391-394

178. Kerb R, Aynacioglu AS, Brockmoller J, Schlagenhaufer R, Bauer S, Szekeres T, Hamwi A, Fritzer-Szekeres M, Baumgartner C, Ongen HZ, Guzelbey P, Roots I, Brinkmann U (2001) The predictive value of MDR1, CYP2C9, and CYP2C19 polymorphisms for phenytoin plasma levels. Pharmacogenomics J 1:204-210

179. Hung CC, Lin CJ, Chen CC, Chang CJ, Liou HH (2004) Dosage recommendation of phenytoin for patients with epilepsy with different CYP2C9/CYP2C19 polymorphisms. Ther Drug Monit 26:534-540

180. Wilson C, Schulz S, Waldman SA (2007) Biomarker development, commercialization, and regulation: individualization of medicine lost in translation. Clin Pharmacol Ther 81:153-155

181. Chiang AP, Butte AJ (2009) Data-driven methods to discover molecular determinants of serious adverse drug events. Clin Pharmacol Ther 85:259-268

182. Ingelman-Sundberg M (2004) Pharmacogenetics of cytochrome P450 and its applications in drug therapy: the past, present and future. Trends Pharmacol Sci 25:193-200

183. Liao G, Zhang X, Clark DJ, Peltz G (2008) A genomic "roadmap" to "better" drugs. Drug Metab Rev 40:225-239

184. Dolinoy DC, Jirtle RL (2008) Environmental epigenomics in human health and disease. Environ Mol Mutagen 49:4-8

185. Gomez A, Ingelman-Sundberg M (2009) Pharmacoepigenetics: its role in interindividual differences in drug response. Clin Pharmacol Ther 85:426-430

186. Epstein RS, Frueh FW, Geren D, Hummer D, McKibbin S, O'Connor S, Randhawa G, Zelman B (2009) Payer perspectives on pharmacogenomics testing and drug development. Pharmacogenomics 10:149-151

187. Feero WG, Guttmacher AE, Collins FS (2008) The genome gets personal-almost. JAMA 299:1351-1352 